\title{
The science and engineering of stem cell-derived organoids-examples from hepatic, biliary, and pancreatic tissues
}

Ogechi Ogoke1, Mitchell Maloy1, Natesh Parashurama1,2

1 Department of Chemical and Biological Engineering, University at Buffalo (State University of New York), Furnas Hall, Buffalo, NY 14260

${ }_{2}$ Clinical and Translation Research Center (CTRC), University at Buffalo (State University of New York), 875 Ellicott St., Buffalo, NY 14203

* Corresponding Author: Natesh Parashurama, 907 Furnas Hall, Buffalo, NY 14260; Tel: 716-645-1201; Fax: 716-645-3822; e-mail: nateshp@buffalo.edu

\section{Running Title: Hepatic, biliary, and pancreatic organoids for regenerative medicine}

Keywords: stem cells, organoids, hepatocytes, pancreatic islets, cholangiocytes, organoid morphogenesis, organoid imaging

\begin{abstract}
Organoid engineering promises to revolutionize medicine with wide ranging applications of scientific, engineering, and clinical interest, including precision and personalized medicine, gene editing, drug development, disease modeling, cellular therapy, and a basic understanding of human development. Organoids are a three-dimensional (3D), miniature, caricature of a target organ, are initiated with stem/progenitor cells, and are extremely promising tools to model organ function. The biological basis for organoids is that they foster stem cell-self renewal, differentiation, and self-organization, recapitulating tissue structure or function better than 2D systems. In this review, we first discuss the importance of epithelial organs and the general properties of epithelial cells to provide context for the liver, pancreas, and gall bladder and rationale for organoid cultures. Next, we develop a general framework to understand self-organization, tissue hierarchy, and organoid cultivation. For each of these areas, we provide historical context, and review both a wide range of biological and/or biophysical/mathematic perspectives that enhances understanding of organoids. Next, we review existing techniques and progress in hepatobiliary and pancreatic organoid engineering. To do this, we review organoids from both primary tissues, cell lines, and stem cells, and introduce engineering studies when applicable. Noninvasive assessment of
\end{abstract}


organoids can reveal underlying biology and enable improved assays for growth, metabolism, and function. Applications of organoid for cell therapy are also discussed. Taken together, we establish a broad strong scientific foundation for organoids and provide an in-depth review of hepatic, biliary and pancreatic organoids.

\section{Contents}

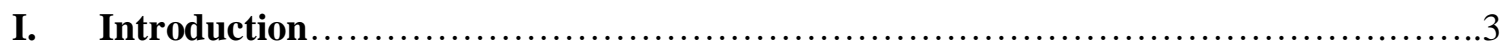

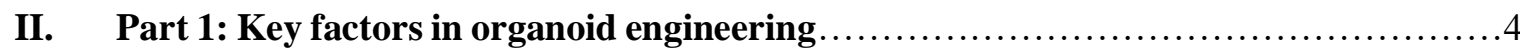

a. Quantitative experimental and mathematical models of tissue organization..........4

b. Cellular hierarchies and composition in 3D organoids...........................5

c. Organoid cultivation..................................................6

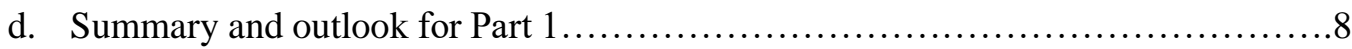

III. Part 2: Hepatic, biliary, and pancreatic organoids ................................

a. Hepatic organoids from transformed or engineered cell lines.....................9

b. Human hepatic organoids (hHO) from primary or fetal tissue....................10

c. Hepatobiliary organoids (hHBO) from adult stem cells and human pluripotent stem

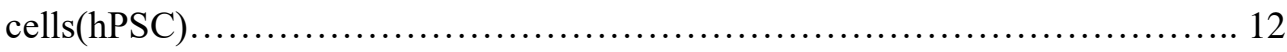

d. Human biliary organoids (hBO) from primary tissue...........................14

e. hBOs from adult stem cells or from hPSC .....................................15

f. Pancreatic organoids.................................................... 17

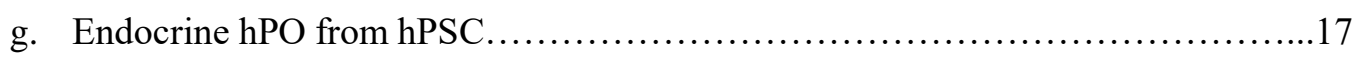

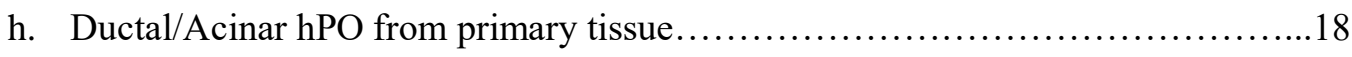

i. Ductal/acinar PO from hPSC ............................................ 19

j. Summary and outlook for Part......................................... 19

IV. Part 3: Imaging Organoids and In vivo transplantation.........................20

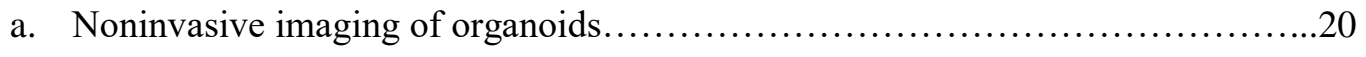

b. Hepatobiliary and pancreatic organoid transplantation........................22

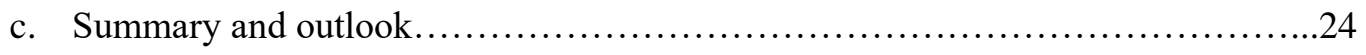

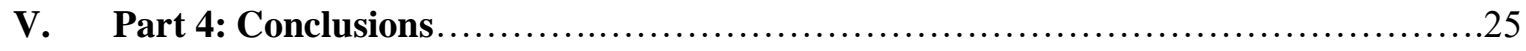

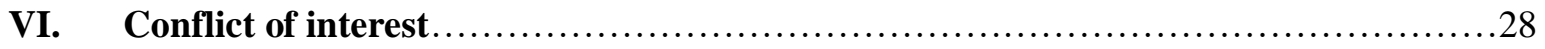

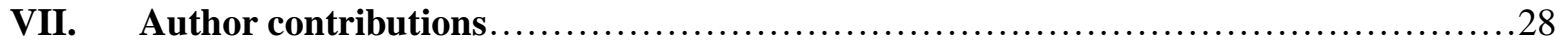

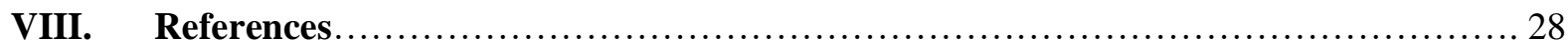




\section{Introduction}

Real organs in the body are comprised of primary cells, not commonly used stable cell lines that express a combination of normal and cancer-related genes. For over 30 years, in a concerted effort to engineer 3D cellular models that are more physiological, scientists and engineers have developed techniques to isolate multiple primary cell types from tissues/organs, and to cultivate these cells in 2D or 3D formats (Duval, Grover et al. 2017). These cultivation techniques are built upon controlling or tailoring cell-cell and cell-matrix interactions, and often employ biomaterial-based scaffolds in addition to natural ones (Ogoke, Oluwole et al. 2017). Other sources of human cell lines, which have provided a foundation for human studies, include patient-derived fetal tissue (Gerlach, Over et al. 2012, Gridelli, Vizzini et al. 2012) and adult tissue from biopsy (Bhogal, Hodson et al. 2011) (Bhogal and Afford 2011). These approaches are a great improvement upon stable transformed cell lines derived from human tumors, or cells that have been transformed to continually proliferate. Pharmaceutical companies often employ these cell lines in studies of toxicity, efficacy, and human disease models (Schwartz, Fridovich et al. 1981, Xu, Hui et al. 2005, Ramaiahgari, den Braver et al. 2014; Yokoyama, Sasaki et al. 2018; Giovannetti, Mey et al. 2004, Woolbright, Bridges et al. 2017, Kim, Choi et al. 2018). Despite their value in enhancing our knowledge of biology and disease modeling, these valuable cells and well-established approaches fail to provide an all-in-one in vitro disease model that captures disease states. Necessary 3D homotypic and heterotypic cell-cell interactions are lacking in these systems, and these cell sources are limited by donorrelated issues, including quality, heterogeneity, and scarcity.

The advent of stem cell biology, engineering, and therapy has provided solutions to these pressing problems brought up by limitations of stable cells and primary tissues. The rapid progression of this field has led to enabled unprecedented access to human tissues. The establishment of efficient differentiation protocols from human pluripotent stem cells (hPSCs), including human embryonic stem cells (hESCs) and human induced pluripotent stem cells, (hiPSC), has enabled several key avenues of research, including: 1) production of many human cells of interest, 2) modeling of diseases in the culture dish, 3) studying human development, 4) gene editing for genetic disease correction, 5) evaluation of hPSC-derived cells for cell therapy (Figure 1), all of which has revolutionized medicine (Shi, Inoue et al. 2017). Despite these unprecedented successes, limitations of hPSC cell culture exist in 2D systems, particularly for epithelial cell types. Epithelial sheets present in embryonic and adult tissues are comprised of epithelial cells which exhibit cell-cell contacts via adherens junctions (homodimeric cadherin proteins), tight junctions (zonula occludens), and cell-extracellular matrix (ECM) contacts to basement membrane, to maintain both structural integrity and barrier function (Lakins, Chin et al. 2012). Epithelial cells also display basal, lateral, and apical membrane domains, each of which has unique membrane proteins and cytoskeletal interconnections. 
These epithelial cell sheets held together tightly bear individual and collective functions in development of organs, and are surprisingly dynamic. Cell sheets dramatically rearrange their shape, in response to changes in tension, during force-driven processes like invagination and tissue folding, and these forces are transmitted through cells (Martin, Gelbart et al. 2010). Further, as opposed to cell division on a culture dish, cell division in an epithelial sheet is probably less common, and may occur by different mechanisms. During cell mitosis in an epithelial cell sheet, an actomyosin contractile ring is connected to the plasma membrane at the equator, and both actin and myosin II generate ring constriction, followed by intercellular bridge formation and cell separation in the plane of the sheet (Le Bras and Le Borgne 2014). These events and others together effect epithelial tissue morphogenesis during tissue and organ development, and ultimately lead to complex 3D architecture within epithelial organs. As a result, even though tissue engineers have generated 3D epithelial tissues that replicate aspects of in vivo architecture (Duval, Grover et al. 2017) by tailoring cell-cell and cell-matrix interactions, and employing biomaterialbased and natural scaffolds (Ogoke, Oluwole et al. 2017). Despite studies tailoring conditions, microenvironments, and materials for cell growth, tissue engineering studies have often been limited by cell source, in terms of the need for harvesting cells from primary human tissues (clinical/surgical biopsies or discarded human tissues), reducing the ability for scale up, and providing reliable and consistent products.

Through these integrated processes during morphogenesis and organ development, epithelial tissues are composed of repeating miniature structural/functional units, like the nephron (kidney), sinusoid (liver), or alveolus (lung). For example, the liver bears single-cell, microscopic hepatic cords that border the sinusoids. From inside out, these hepatic cords are comprised of hepatocytes, the functional cells of the liver, adherent stellate cells, the space of Disse, fenestrated endothelial cells which line the hepatic sinusoids, and Kupfer/immune cells. Within the liver is the biliary tract, branching tissue lined by single bile duct (cholangiocytes) cells that transport bile to the gall bladder where it is stored and released. Another complex organ, the pancreas, contains a series of branching ducts and glands that secrete pancreatic juices during digestion and islets comprised of several cell types such as the insulin-producing $\beta$-cells that are destroyed in type I Diabetes Mellitus. Unfortunately, these 3D structures, forged during morphogenesis, can't be fully modeled in 2D using traditional hPSC-derived protocols. Along these lines, fully mature hPSC-derived liver, biliary, and pancreatic cells have been difficult to differentiate in these traditional 2D systems (Zhu, Rezvani et al. 2014, Nair, Liu et al. 2019; Cho, Parashurama et al. 2008; Parashurama, Nahmias et al. 2008, Ogawa, Ogawa et al. 2015). Fortunately, in an effort to further push organotypic models, scientists and engineers have begun to employ hPSC-derived progenitors, adult stem cells, and mature primary cells to engineer organoids (Figures 1-2). These subtle but potent cellular systems are providing breakthroughs previously not seen in biomedicine. However, there remain many general 
questions regarding these systems: 1) What are the key factors in constraining and controlling their growth and how can this be described mathematically? 2) What governs their cell composition? and 3) What are the best cultivation techniques? These are important questions which we review below.

\section{Part 1: Key factors in organoid engineering}

In this section, we focus on critical aspects of organoid engineering, including how tissues organize, the importance of cell composition, and of cell cultivation.

\section{Quantitative experimental and mathematical models of tissue organization}

After embryo implantation, a series of orchestrated events follow including embryogenesis, gastrulation, tissue patterning and organ formation. Each of these predictable but complex processes are imbued with self-organization of cells, and involves morphogenic (cell-cell signaling, cell motility and differentiation ) biophysical cues, coordinated gene activation/suppression, leading to formation of the body plan and organogenesis (Tam and Loebel 2007). As mentioned above, many simultaneous processes effect tissue organization. For example, in C. elegans, specific proteins have been identified that maintain apicobasal polarity (Harrell and Goldstein 2011), while myosins allow internalization of the endodermal cells (Harrell and Goldstein 2011). Furthermore, small molecule disruption of the actomyosin cortex and the plasma membrane strongly affects directed cell migration of mesendoderm in zebrafish (Diz-Munoz, Krieg et al. 2010). The relevance of the epithelial transitions (i.e. simple to pseudostratified, hepatoblast migration) is not known, and better models are needed to elucidate these epithelial phenomena and their effects on liver growth (Nakaya, Sukowati et al. 2013). Cell polarity markers, which may not be present in vitro, need to partitioned correctly, while separate forces are involved in spindle positioning and in cytokinesis (Le Bras and Le Borgne 2014). Epithelial-mesenchymal transitions (EMT, MET in reverse) are also a critical process in morphogenesis, and are involved changes in gene expression and cell behavior (Nakaya and Sheng 2013). Cell-ECM interactions are critical as well, in terms of interactions between epithelial cell sheets and the underlying basement membrane. Cell surface integrins, a complex family of heterodimeric transmembrane proteins, cluster and bind to extracellular matrix (ECM) proteins (laminin, fibronectin, and collagen) (Ezzell, Goldmann et al. 1997; Levental, Yu et al. 2009, Paszek, Boettiger et al. 2009). These clusters, termed focal adhesion complexes, transmit mechanical cues from the external environment, across the membrane, to the actin cytoskeleton, and indirectly to other structural elements such as microtubules (Simerly, Navara et al. 2004), and intermediate filaments (Erickson, Tucker et al. 1987). Overall, cell tension, biophysical signaling and cellular responses together influence morphogenesis of epithelial tissues. 
Traditionally, embryos were dissociated and reaggregated to study self-organization. However, a series of seminal papers demonstrated that hPSC-derived progenitors can self-organize and undergo morphogenesis when cultured in suspension culture in the absence of scaffolds. The tissues include polarized cerebral cortex (Eiraku, Watanabe et al. 2008), optic cup (Eiraku, Takata et al. 2011; Nakano, Ando et al. 2012), anterior pituitary (Suga, Kadoshima et al. 2011), and cerebellum (Muguruma, Nishiyama et al. 2015). In concert with this, cerebral organoids were engineered (Lancaster, Renner et al. 2013), with the assistance of continuous culture in spinner flasks. While these studies focused generally on the nervous system, other studies have demonstrated kidney organoids (Takasato, Er et al. 2015), self-organizing single intestinal crypts/villus (Sato, Vries et al. 2009), gut tube (Spence, Mayhew et al. 2011), in addition to hepatobiliary and pancreatic organoids reviewed in Part 2 of this review.

In addition to self-organization of adult tissues, scientists have improved models of embryogenesis using hPSC. PSC culture traditionally employed embryoid bodies, or when self-organized, gastruloids, the latter of which demonstrate high levels of self-organization (Warmflash, Sorre et al. 2014; Libby, Joy et al. 2018, Zheng, Xue et al. 2019), and these studies have been reviewed elsewhere (Deglincerti, Etoc et al. 2016; Simunovic and Brivanlou 2017). A major question is what are the fundamental principles of tissue formation at the size/scale of an organoid? Since self-organization within embryos has been analyzed using mathematical and physical laws, a key question is can organoid i.e. self-organization of organoids be analyzed the same way? Mathematical modeling and simulations have been used to answer this question, with approaches including a differential cell adhesion hypothesis based upon minimization of cell surface energy applied to chick embryos (Steinberg 1963), mechanical force-based modeling to analyze the epidermal layer of fish, movements within epithelial layers, and optic cup morphogenesis from human stem cells (Weliky and Oster 1990; Fletcher, Osterfield et al. 2014; Okuda, Takata et al. 2018). It remains to be seen how mathematical models can be applied to human organoid data to predict morphogenesis or spatial patterning. For example, an important question is, can organoids generate forces required for tissue bud morphogenesis? Another aspect of organoid self-organization is whether gene expression is coordinated during this process. Seminal studies of developmental genetic regulatory networks that dynamically control gene expression (Britten and Davidson 1969) opened a new field of investigation and led to a deeper understanding of the mechanisms by which transiently expressed master regulatory factors progressively regulate lineage decisions during embryonic development, and these models have been used to explain development of the body plan and endoderm germ layer (Peter and Davidson 2011). A key question is, do developmental gene networks function to create tissue patterns in organoids, and do these tissue patterns resemble the in vivo process?

\section{Cellular hierarchies and composition in 3D organoids}


Since organoids are derived from adult stem cells or PSC-derived stem/progenitor cells, and tissues are organized in a hierarchical fashion (Visvader and Clevers 2016), organoids themselves are likely hierarchically organized, leading to a complex cellular composition and what is termed "cellular heterogeneity." The best method to analyze cellular heterogeneity in organoids is single cell RNAsequencing, a powerful tool to compare gene expression levels in single cells. Consistent with this, RNAseq analysis of mouse intestinal organoids, derived from Lgr5 mouse intestinal stem cells, demonstrated 5 clusters after analysis, including: 1) enterocyte, 2) secretory cells (enteroendocrine cells, goblet cells, Paneth cells), 3) transit amplifying cells, 4) Lgr5+ stem cells, and 5) rare enteroendocrine cells, indicating underlying cell complexity (Grun, Lyubimova et al. 2015). Similarly, RNA-seq analysis of hPSC-derived whole cerebral organoids (days 33-65) and microdissected cortical regions resulted in 11 clusters, including: 1) various neural progenitor cells subtypes 2) neurons from dorsal forebrain, telencephalic, hippocampus, and ventral forebrain, 3) cycling and noncycling progenitors, and 4) cycling and noncycling mesenchymal cells. (Camp, Badsha et al. 2015). These studies indicate that even though the starting population is considered uniform, there is considerable cellular heterogeneity within organoids. These studies indicate that the cellular heterogeneity mimics in vivo tissues, but further investigations should elucidate how to improve modeling of cellular heterogeneity within organoids.

Cellular composition is also an important aspect of organoid engineering. The best example of the significance of cellular composition in hepatic organoids engineered is liver-bud like organoids composed of hPSC-derived hepatic progenitors, human mesenchymal stem cells (hMSC), and human umbilical vein endothelial cells (HUVEC) (Takebe, Sekine et al. 2013). This study and a subsequent protocol (Takebe, Zhang et al. 2014) outline the technique to engineer a liver bud-like tissue, using an empirically determined ratio of iPSC-derived hepatic progenitors to HUVECs to hMSCs of 10:7:2 (Takebe, Zhang et al. 2014). Other studies have validated the use of these types of cell ratios for the repeating the same organoid system (Ramachandran, Schirmer et al. 2015). While these studies help underscore the importance of cell composition in engineering organoids, understanding how initial organoid cell composition affects the final state, and how changing the relative ratios of cells and their properties (i.e. proliferation rate) remains unknown. We highlight the importance of cell-cell composition in Figure 2. It is importance to consider the cell fate within the organoid. Cells may engage in heterotypic and homotypic cell contacts, migrate, differentially proliferate, change packing density by contracting or expanding, or differentiate. The single kinetic steps that take place during this process, and how they vary with cell composition, remains to be determined. Since there are so many variables involved, it is possible that mathematical modeling can be utilized to determine the underlying fundamental of the process. This may enable us to answer the question, "If the proliferation rate of supporting cell doubles, what happens to the organoid, as a system?" Improved 
organoid imaging (reviewed below), including dynamic imaging, will also greatly enhance our understanding of how cell composition of organoids affects cell fate.

\section{Organoid cultivation}

Given that organoids phenocopy tissue hierarchy and potentially 3D tissue microarchitecture, important questions are: 1) how they are cultivated? 2) what are the principles? and 3) what are the current limitations? Organoids are cultivated by seeding hPSC-derived progenitors or adult stem cells with cultivation systems that promote aggregation such as hanging drop technique, non-adherent tissue culture plates, or non-adhesive microwell culture, either in suspension or submerged in extracellular matrix like MG, a soft protein hydrogel of mouse origin which bears many major extracellular matrix proteins (Figure 3). By definition, organoids can be passaged extensively. Within the organoid, cells likely remodel the extracellular matrix which then enables them to engage B-integrin receptors needed for cell mechanosignaling (Lin, Chou et al. 2006). Additionally, these cultivation formats promote epithelial sheet formation, mediated in part by cadherin receptors (Lin, Chou et al. 2006). The combined cell-cell and cellmatrix interactions are critical to coordinate self-organization and coordinated gene expression, but a major question is what other principles govern this process? Fortunately, a great deal of research has been conducted analyzing tumor growth in spheroids, and the physical principles are likely analogous to organoid formation. In suspension, tumor spheroids undergo growth arrest due limitation of nutrients in the center, including oxygen, in part due to diffusion limitations which would occur is suspended spheroids (Roose, Netti et al. 2003). These restrictive conditions can be alleviated through cultivation configurations like rotating flasks or spinner flasks (Glicklis, Merchuk et al. 2004) and these systems have been critical of large brain organoids (Lancaster, Renner et al. 2013).

Interestingly, when submerged in gels rather than in suspension, diffusion limitations do not limit tumor growth. Seminal studies demonstrated that cell line-derived multicellular tumor spheroids do not grow in agarose gels of varying concentration, and were approximately 2-10 times less diameter than in suspension. Gompertzian-based mathematical models have been used to demonstrate that imposed solid stress from agarose did not change proliferation rate or clonal efficiency, and in fact decreased apoptosis, suggesting that smaller spheroids at higher stresses have a higher packing density of cells (Helmlinger, Netti et al. 1997). Further, this study determined that mechanical stresses of 50-120 mm Hg were present at varying gel concentrations. This suggests that a local threshold of stress develops to stop 3D growth (Helmlinger, Netti et al. 1997). Further, experimental depletion of collagen, hyaluronan, fibroblasts and tumor cells reduced stress and enhanced tumor growth (Stylianopoulos, Martin et al. 2012). Unfortunately, how limitations in nutrients and oxygen, and solid stress affects self-organization, organoid hierarchy, or overall growth is not known. Special attention to culture medium, generation and removal of waste 
products, and solution conditions is therefore further warranted. In light of this fact, cultivation may require spinner flasks, bioreactors, or improved perfusion which use flow to remove wastes and promote growth.

Although high throughput systems offer advantages for screening of compounds for differentiation, growth, morphogenesis, as well as for combining disease modeling with drug development. However, organoids have been challenging to incorporate into high throughput systems because of their heterogeneity, 3D shape, size, morphology, nutrition, traditional microwell-based strategies. After high content screening of the levels of Zika infection in neural progenitor cell with small molecules, Zika infected hPSC-neural organoids, which provided a model of brain growth disorders, were successfully evaluated with lead candidates (Zhou, Tan et al. 2017). An engineered, microwell-based "microraft array" system was used to screen compounds that enhance Paneth cell (niche cell)-intestinal stem cell interactions leading towards organoid development (Gracz, Williamson et al. 2015). A technique termed "automated multidimensional phenotyping" was utilized for screening molecules that enhance hPSC-derived kidney organoid differentiation towards various kidney cell subtypes, assessed by traditional immunostaining (Czerniecki, Cruz et al. 2018). This study employed disease modeling and screening of candidate drugs, and identification of potential drug candidates. Other engineering systems that combine high throughput screens and organoids from multiple tissues to create body-on-chips have been recently reviewed (Skardal, Shupe et al. 2016), highlighting the connection between organoids, high throughput systems, and technology.

\section{Summary and outlook for Part 1}

The development of human stem cell-derived organoids has heightened investigations cutting across parallel and historically important areas including epithelial morphogenesis, tissue organization, cellular hierarchies, and organoid cultivation. Key aspects of investigation into tissue organization includes including animal models of embryogenesis, organogenesis, and morphogenesis, including mathematicalbased approaches and their applications to including self-organized human stem cell-derived tissues, like the optic cop, or self-organized germ layers, like gastruloids. Further, organoids give rise to cellular heterogeneity termed tissue/cellular hierarchies, which enables unprecedented access to analysis of factors, that control stem cell self-renewal as well as proliferation and differentiation of progenitors in an in vivo like environment. Moreover, methods applied to spheroid cultures developed in the field of bioengineering are applicable to organoid cultivation, which helps address problems of heterogeneity, control of size and shape, and scale up. Finally, coupling high throughput technologies with organoid technologies has enabled important approaches of improving differentiation as well as disease modeling combined with drug screening. 


\section{Part 2: Hepatic, biliary, and pancreatic organoids}

Organoids for hepatic, biliary, and pancreatic organs have been challenging to engineer in part because of their transcriptional complexity, complex functions and complex microstructure. These critical organs are comprised of multilayered epithelial and mesenchymal microstructures in unique configurations. In the case of the liver, single cell thick sheets are bordered on two sides, by microscopic vascular channels (sinusoids) lined with specialized endothelial cells, called liver sinusoidal endothelial cells (LSECs) (Ogoke, Oluwole et al. 2017). Further, the biliary tree, which is lined with biliary duct cells, or cholangiocytes, carries bile from the liver to the gall bladder and to the gastrointestinal tract, is integrated with hepatic cords and hepatic vasculature. This complex liver microstructure is critical to normal function and is disrupted/inflamed in diseases like liver fibrosis, due to repeat hepatocellular injury from various ailments, leading to diseases like primary sclerosing cholangitis (PSC). The pancreas is a somewhat fragile organ composed primarily of endocrine, ductal, and acinar tissues. The complexity of the endocrine compartment is apparent in the large number of parenchymal cell types (nine) within the pancreatic islet, and physiologic control in response to widely varying glucose load during the day. Major diseases of the pancreas, including pancreatic cancer, type I diabetes mellitus, and pancreatitis, represent incurable medical problems which need improved modeling (Ellis, Ramzy et al. 2017). In this section, we review hepatobiliary and pancreatic organoids from cell lines, from primary tissue, and from stem cell-derived tissues.

\section{Hepatic organoids from transformed or engineered cell lines}

Progress in hepatic organoids (HOs) has demonstrated key aspects of organoid engineering over the last 15 years. The liver is the largest internal organ, consisting of approximately 200 billion hepatocytes in adults, with over 500 known functions (Ogoke, Oluwole et al. 2017). The hepatocytes, which provide liver functions, and the cholangiocytes (biliary epithelial cells), which line the branching biliary ducts, are derived from hepatic-specified endoderm, which arises at the earliest stages of the liver bud during liver development (Si-Tayeb, Lemaigre et al. 2010). In addition to hepatocytes and intrahepatic and extrahepatic biliary epithelial cells, the liver is composed of several mesoderm-derived cells including LSECs, hepatic stellate cells (HSCs), and Kuppfer/immune cells. Although by definition they are not human HOs (hHOs), hepatic spheroids composed of immortalized human cell lines can mimic structure and function of the in vivo tissue, can be passaged extensively. Widely used hepatic cell lines (e.g. HepG2) have been used to engineer hepatic epithelium within 3D spheroids with enhanced basolateral polarity, hepatic gene expression, and albumin function (Ramaiahgari, den Braver et al. 2014). Moreover, these MG-embedded HepG2 spheroids can exhibit phase 1 and 2 drug metabolism enzymes and transporter activity similar to mature hepatocytes. However, scientists have proposed that observed enhancement in function may not be due to spheroid/MG format, but instead due to length of spheroid cultivation (Luckert, Schulz et al. 2017), 
suggesting further investigated is needed. Another cell line tested in the spheroid format is the HepaRG cell line, which has demonstrated mature functions and bipotent differentiation (Cerec, Glaise et al. 2007). HepaRG engineered into spheroids were used to understand mechanisms of cholestasis, a major type of drug-induced liver injury, and specifically chlorpromazine-induced cholestasis (Hendriks, Puigvert et al. 2016). These studies demonstrated the importance of spheroid approaches for analysis of drug metabolism hinting at the potential value of engineering hHOs.

Since hepatic co-culture stimulates hepatic function (Bhatia, Balis et al. 1998) and hepatic differentiation (Cho, Parashurama et al. 2008), one concerted approach to engineering hHOs has been cocultivation, which better mimics hepatic microarchitecture. As mentioned above, self-renewal of organoids is a key aspect of organoid technology. A recent study explored self-renewable cells that were commercially available, cell lines that had been engineered using Upcyte technology (Ramachandran, Schirmer et al. 2015). This technology (Burkard, Dahn et al. 2012; Levy, Bomze et al. 2015) enables conditional activation of viral genes to promote proliferation of mature parenchymal cells. Hepatocytes, LSECS, and hMSC engineered with Upcyte technology were co-cultivated in 3D formats on MG, where they self-condensed similar to a previous study that employed primary cells and hPSC (Takebe, Sekine et al. 2013). These hHOs were cultivated long term in flow-based bioreactors and demonstrated that secretory and P450 enzyme expression was similar to mature hepatocytes, component cells could be passaged, and organoids self-renew (Ramachandran, Schirmer et al. 2015). However, these hHOs did not exhibit the spatial organization of the liver, reproducibility in spatial architecture between organoids was lacking, and organoids lacked biliary functions. This highlights a major concept regarding the concept of cell source for engineering hHOs; the importance of spatial organization and the need for a biliary component.

Incorporating technology for improved scaffolds represents another approach for augmenting reproducibility and scalability of spheroid/organoid culture. Interestingly, $5 \mathrm{~mm}$ x $5 \mathrm{~mm}$, hemispherical, microstructured, biocompatible, polycarbonate microporous (2-4 $\mu \mathrm{m})$ scaffolds (MatriGrid) were engineered for spheroid/organoid culture. These scaffolds were engineered into a bioreactor system, which improved culture by removal of waste products by maintained/enhanced supply of oxygen and nutrients. This bioreactor system demonstrated the maturation of liver functions in 3D flow culture compared to static culture (Fernekorn, Hampl et al. 2015), although the level and extent of functional improvement was not clear. In addition to technologies like tissue engineered scaffolds, encapsulation technology has also been used to improve reproducibility of 3D spheroid formation. Droplet-based microfluidics was used to produce a monodisperse, portable, "organ in a droplet," within a biocompatible 3D core shell scaffold with an $\mathrm{H}_{2} \mathrm{O}$ core and an alginate calcium shell (Chen, Utech et al. 2016). In these droplets, hepatocytes within the core are encapsulated and subsequently engulfed in a second layer of fibroblasts within the shell. These mixed culture spheroids exhibited enhanced functions with coculture, similar to adult hepatocytes (Ortega-Prieto, 
Skelton et al. 2018). Collectively, these studies demonstrate advantages and limitations of existing spheroid approaches with cell lines, and the potential advantages of using bioreactor, materials science, and encapsulation technology.

\section{hHO from primary human or fetal tissue}

Compared to using mature parenchymal cells that are terminally differentiated, hepatoblast-like hepatic progenitor cells have the potential to divide and differentiate, and may better self-organize into a liver-like 3D tissue. In one of the first studies of hHOs, donor (adult) small human hepatocytes (SH) and nonparenchymal liver cells cultured in an organoid format within collagen sponges processed from bovine tendon, demonstrated functional hepatocyte-like cells that were spatially segregated to the outer layer, some biliary duct formation, and surrounding vascular structures (Sugimoto, Harada et al. 2005). This study demonstrated several principles of organoids, including the use of progenitors, spatial segregation and aggregation, morphogenesis, and differentiation. The fetal liver is a rich source of hepatoblasts and proliferative cells (Tanimizu, Nishikawa et al. 2003). Since hepatoblasts are bipotent for both hepatic and biliary fates, human fetal progenitors are a potentially valuable cell source for hHOs. Human fetal liver progenitors cells between 18 and 21 weeks of gestation were cultivated with liver decellularized scaffolds that were engineered into $8 \mathrm{~mm}$ discs for 3 weeks of culture (Vyas, Baptista et al. 2017). Interestingly, a wide range of biliary phenotypes were obtained, including immature and mature biliary ducts exhibiting key functional markers, demonstrating both hepatic and biliary differentiation. By enabling formation key cell types, these hHOs address a direct limitation of previous approaches. However, these hHO within scaffolds were not passaged and this key aspect of hhO was not tested.

Recent studies have changed the landscape regarding HOs and their ability to be passaged, to exhibit cellular functions, and to reverse disease in immunodeficient mice. Although adult hepatocytes do not replicate appreciably in vitro, recent studies have demonstrated in vitro proliferative activity of primary hepatocytes (Hu, Gehart et al. 2018; Huch, Dorrell et al. 2013; Peng, Logan et al. 2018). Isolated mouse hepatocytes (from multiple strains) were shown to be cultivated under a variety conditions to result in hepatocyte-like clustered (grape-like) mouse HO (mHO) (Hu, Gehart et al. 2018). However, plating efficiency was low, growth occurred but slowed down at 2-3 months, and cell labeling studies demonstrated that $\mathrm{mHO}$, were derived from albumin-positive hepatocytes rather than ductal cells (Hu, Gehart et al. 2018). Interestingly, Axin +2 hepatocytes, which have been shown to give rise to hepatocytes, self-renew, and respond to Wnt 2 and Wnt9b secreted by central vein endothelial cells (Wang, Zhao et al. 2015), generated more mHO than adult hepatocytes, likely due to their increased proliferative capacity. These mHOs demonstrated stability and reproducibility of gene expression with continued passaging, and were cultured in serum-free HO medium containing 15\% R-spondin (Wnt agonist) conditioned medium, EGF, CHIR, 
nicotinamide, HGF, A83-01 (TGFß inhibition), FGF7, FGF10, and gastrin (Hu, Gehart et al. 2018). During culture, these mHOs expressed liver markers, had undetectable biliary markers, but expressed the fetal marker AFP together with other genes that are upregulated in hepatocytes during regeneration after hepatectomy. Interestingly, upon single cell RNA-seq analysis of mHOs, 5 clusters of cells were apparent, including non-cycling mature hepatocytes, 2 clusters of hepatic progenitors, a primitive cycling population, and a population expressing biliary markers indicating transdifferentiation. In the same study, hHO were also generated from primary fetal and adult hepatocytes. The HO medium had to be optimized with the addition of ROCK inhibitor and TGF $\alpha$. Under these conditions, fetal hepatocyte-derived hHOs were cultivated as long as 11 months in culture with 28 passages. Further, the hHO from primary hepatocytes demonstrated many subcellular hepatocyte structures, albumin function comparable to adult hepatocytes, and repopulation upon transplantation, but limited expansion (2-2.5 months) in vitro. Fetal hHO generated networks of bile canaliculi in vitro, while more mature fetal hHO expressed mature liver markers. Singlecell RNA seq of the fetal hHO demonstrated several clusters of cells, including a mature cluster, a mesenchymal marker, two liver progenitor markers with some genes similar to regenerating hepatocyte, but not biliary markers. The fetal hHO also successfully repopulated liver and generated albumin upon transplantation in transgenic mouse models (Hu, Gehart et al. 2018).

In a second study of $\mathrm{mHO}$ (Peng, Logan et al. 2018), scientists found that mouse hepatocytes could be expanded as mHO when basal medium (William's E medium, B27, N2, nicotinamide, $1.25 \mathrm{~N}-$ Acetylcysteine, ROCK inhibitor, A8301) was supplemented with CHIR, EGF, and 100 ng/ml TNF. Amazingly, these supplements increased organoid plating efficiency to $15 \%$, resulting in grape-like structures similar to the above study (Hu, Gehart et al. 2018), required TNF $\alpha$-mediated NF-kB, and resulted in passaging up to 8 months in vitro. These structures demonstrated bile canaliculi within the $\mathrm{mHO}$, and periportal vs. pericentral genes could be differentially upregulated. RNA-seq analysis demonstrated that $\sim 1 / 5$ of the cells within the $\mathrm{mHO}$ expressed proliferation markers. Amazingly, these mHOs repopulated the Fah -/- acute mouse liver injury models at $80 \%$, which is much higher than the $1 \%$ repopulation expected. Interestingly, large clusters in the liver expressed Axin 3, indicating they were involved in Wnt signaling that normally expands proliferative capacity of hepatocytes (Wang, Zhao et al. 2015). Consistent with this, R-Spondin was expressed at the periphery of these large clusters in injury zones. These studies demonstrated culture conditions for $\mathrm{mHO}$ and greatly enhanced proliferation in vivo.

\section{Hepatobiliary organoids (HBO) from adult stem cells and human pluripotent stem cells (hPSC)}

HBO have been engineered from mouse and human adult stem/progenitor cells in the liver (Huch, Dorrell et al. 2013; Huch, Gehart et al. 2015). Adult liver stem/progenitor cells and hPSC-derived hHO are 
advantageous because of their inherent self-renewal and proliferative ability. Adult hepatic and/or biliary progenitor cells have been previously studied in the context of regenerative capacity of liver tissue after acute and chronic injury. Activated resident liver cells following a chronic injury can transdifferentiate into oval cells that can form both hepatocytes and cholangiocytes (Huch, Dorrell et al. 2013; Huch, Gehart et al. 2015). Further, as mentioned above, Wnt-stimulated pericentral hepatocytes also have regenerative capacity, and Wnt-responsive hepatocytes express Axin 2 in hepatocytes (Wang, Zhao et al. 2015). Although identifying an adult stem/progenitor cell in the liver, this study did not employ mHO. Another Wnt-sensitive marker is Lgr5, and recent studies employ biliary ductal cells and their subsets, including Lgr5+ and EpCAM+ biliary duct cells, to generate HBO. It was shown that the stem cell/progenitor Lgr5 was activated in a Sox9+ biliary ductal population upon $\mathrm{CCl}_{4}$-induced injury. Since Lgr5+ epithelial cells have been employed to generate organoids, biliary fragments, single Lgr5 positive cells (from $\mathrm{CCl}_{4}$ injured livers) were embedded in MG and grew in the presence of EGF, R-Spondin1 (Wnt agonist), Fgf10, HGF, and Nicotinamide (Huch, Dorrell et al. 2013). These Lgr5+ HBO grew, expressed ductal markers, and were maintained for 12 months by weekly passaging, expressed progenitor markers Sox9, Cd44, Prom1, and expressed both hepatocyte and ductal markers, indicating they were bipotent. Further, the inhibition of Notch and TGF-beta signaling demonstrated transcriptional activation of hepatocyte-specific genes and down regulation of Lgr5, indicating the cells had differentiated, and were able to repopulate injured liver in Fah -/- mice which model liver injury (Huch, Dorrell et al. 2013). EpCAM+ cells have also been used successfully for patient-specific disease liver modeling (Hu, Gehart et al. 2018). These studies summarize that both Lgr5+ cells and EpCAM+ cells are adult stem cell-like populations that can be used to successfully generate both $\mathrm{mHBO}$ and hHBO that can be passaged long term, and are bipotent for liver and biliary epithelial cells.

Advantages of hPSC-derived hHBOs are the infinite self-renewal capacity, and the improved ability for patient-specific cells and disease modeling. Further, hPSC-specifically are valuable because of the unlimited proliferative and differentiation capacity the hPSC-hepatic endoderm/hepatoblasts, and the ability to obtain patient-specific hPSC. Combining the strength of hPSC with the strength of using nonparenchymal cells normally present in the liver would strengthen hHBO modeling. Using this novel approach, scientists first differentiated hPSCs into hepatic progenitor cells in monolayer culture (Figure 4), and then employed MSC to model hepatic stellate cells (HSC), and HUVEC (human umbilical vein endothelial cells) to model early liver bud endothelial cells (Takebe, Sekine et al. 2013). These cells were mixed at pre-defined ratios and cultivated on MG resulting in standalone structures which contract to the form a miniature disc. These miniature discs were analyzed and demonstrated gene expression comparable to mouse liver bud, and when transplanted, became vascularized, exhibited liver-specific gene expression, and reverse liver injury in mouse models. How these systems work is still being investigated, including 
understanding intercellular signaling which appears to be between HUVEC and hPSC-hepatic endoderm (Asai, Aihara et al. 2017). A key aspect of organoid technology is the ability to scale-up the system such that hHOs are reproducible, and these hHOs have addressed these and other bioprocessing strategies (Takebe, Sekine et al. 2017). Although these hHOs had several advantages, they used hMSC instead of actual HSC.

Improvements in $\mathrm{HO}$ technology can involve cell composition, improved scalability, and application for disease modeling. Along these line, PSCs have been engineered into HSCs. The PSC-HSCs closely mimic primary human HSCs at the transcriptional, phenotypical, and functional levels. When cocultured as 3D spheroids with HepaRG hepatocytes, PSC-HSCs demonstrated a quiescent phenotype. Importantly, they mount a fibrogenic response and secrete collagen in reaction to external stimuli, similar to pathologic responses in vivo (Coll, Perea et al. 2018). This could greatly improve disease modeling. Technology-based approaches have improved the scalability of hHOs. A recent study generates liver-budlike structures using extracellular matrix (ECM)-coated, PEG-hydrogel spherical arrays of miniature wells that are $\sim 140 \mu \mathrm{m}$ in diameter (Ng, Saeb-Parsy et al. 2018), significantly smaller than most organoid sizes. Immature PSC-derived hepatic progenitors were seeded in these wells and matured for 14 days, and compared to controls (spheroid culture, and monolayer culture) demonstrated enhanced function and evidence of maturation. Interestingly, these hHO demonstrated evidence of enhanced cell polarity, tissue integration and angiogenesis upon transplantation, and demonstrated that combined TGFß pathway and Sonic hedgehog pathway (Shh) signaling were involved in organoid formation. This system is scalable, although the cellular structures were heterogeneous in size, and long term cultures in these dense systems was not tested.

Organoid technology has also been used to firmly establish putative stem/progenitor cell populations within fetal and adult liver. For example, Sox 9 expressing cells with the surface phenotype CD45- CD31- MIC1-1C3+ within adult livers were evaluated for their ability give rise to adult hepatocytes, were shown to be clonogenic in single cell organoid assays, demonstrating they could be passaged for 3 months (Tarlow, Finegold et al. 2014). Another study by the same group studied the clonogenicity of an epithelial, ductal cell subpopulation with the phenotype of MIC1-1C3+/CD133+/CD26- expressing Sox9/FoxJ1 that was present in both mouse liver and mouse pancreas, and demonstrated that pancreatic derived organoids had liver differentiation potential in vivo (Dorrell, Tarlow et al. 2014). Furthermore, in a study of human fetal and adult liver, a new stem/progenitor subpopulation was identified, a CD235a-/CD45-/EpCAM+/NCAM+ population, that expresses both biliary and hepatic markers. Clonogenic organoid assays were performed, demonstrating that organoids could be differentiated to form both biliary epithelial cells and hepatocytes (Segal, Kent et al. 2019). These studies collectively highlight numerous subpopulations identified through sorting and organoid formation. 
Overall, we have summarized the extensive activity for engineering $\mathrm{HO}$ from cell lines, mouse and human hepatocytes, from adult liver stem/progenitor cells, and human PSC. These landmark advances have been based upon careful investigation of improvements in medium conditions for growth, an understanding of key organoid fundamentals, the utility of liver injury models, and the ability to apply principles of liver stem cell biology, regeneration, inflammation, organ development, and RNA-sequencing technology to hHO in culture. While there have been many advancements in hHO based disease modeling, we feel these studies are out of the scope of the current manuscript. With the establishment of organoid approaches,

\section{Human biliary organoids (BO) from primary tissue}

Cholangiocytes, or bile ducts cells, line the bile ducts as part of the intrahepatic and extrahepatic biliary duct system. These rare cells $(\sim 3 \%$ of the liver) regulate bile composition and transport bile containing metabolized drugs, cholesterol, and bile salts. A single layer of cholangiocytes line bile ducts. Furthermore, because a large number hydrophobic drugs are metabolized by Phase I and Phase II enzymes, conjugated, and secreted into the bile, they are key cells in models of drug metabolism and hepatoxicity. Further, diseases of the biliary tract are a major cause of cirrhosis and subsequent pediatric and adult liver transplantation. As primary cholangiocyte culture remains problematic, a recent human biliary organoid hBO technique was established using isolation of primary extrahepatic biliary cells, followed by in vitro culture (Sampaziotis, de Brito et al. 2017). In the presence of various growth factors, these cells selforganize into hBOs consisting of tubular structures, which express cholangiocyte markers in vitro. Further, they can be serially passaged for 20 times with no phenotypic changes, suggesting they undergo selfrenewal. Interestingly, these hBOs could be dissociated, and were able to repopulate biodegradable, polylactic-co-glycolic acid (PLGA) scaffolds with ease, indicating hBO culture can enable primary cholangiocyte engraftment in scaffolds. However, these results could potentially be explained by the fact that the isolation procedure may have yielded biliary tree stem cells (BTSC), rather than cholangiocytes.

Another approach to generating cholangiocytes is through de-differentiation of adult hepatocytes and re-specification towards a cholangiocyte fate. In the presence of hepatocyte growth factor (HGF) and epidermal growth factor (EGF), hepatocytes form 3D structures in which the surface of tissue is covered by a superficial layer of biliary epithelial cells (Michalopoulos, Bowen et al. 2001). This hBO is also comprised of an intermediate layer of connective tissue, hepatocytes, and a basal layer of endothelial cells. This system takes advantage of hepatocyte to biliary epithelial cell transition (Michalopoulos, Bowen et al. 2002). Trans-differentiation has also been reported in the presence of other soluble factors (Limaye, Bowen et al. 2008) and key ECM configurations (Sugimoto, Harada et al. 2005). As fetal tissue has become 
a more restricted cell source, this approach could be critical cell source for hepatobiliary tissue within organoids. Thus, primary cholangiocytes can form hBOs and potentially transdifferentiated biliary have been used to form mixed hBOs.

\section{hBO from adult stem cells or from hPSC}

As mentioned above, mouse Lgr5+ stem/progenitor cells within the Sox9+ biliary ductal population were shown to generate hepatocyte-like cells (Huch, Dorrell et al. 2013). Using the same approach, these organoids were differentiated into cholangiocytes-like cells, which exhibited numerous functional properties of cholangiocytes. To identify subsets of stem/progenitor cells within liver, scientists found that MIC1-1C3+ (biliary) (Dorrell, Erker et al. 2008) stains nonparenchymal cells in the liver under injury conditions that induce oval cells. Building on this, a subset (MIC1-1C3+, CD45-, CD11b-, CD31-, CD26) of liver nonparenchymal cells demonstrated clonogenic activity and association with Sox9 and FoxJ1, and could give rise to both hepatocytes and ducts even in the absence of liver injury, indicating a bipotential/ population. Building on this, scientists used the progenitor cell subset, performed further analysis of cell surface marker, and identified that ST14 (hi) cell population had increased organoid forming activity. (Li, Dorrell et al. 2017). In another study, organoid-derived cholangiocytes were integrated intro polyethersulfone hollow fiber membranes to give rise to physiologic bile ducts (Chen, Jochems et al. 2018). In this case, the organoids enabled expansion of cholangiocyte-like cells that could be isolated and used for their regenerative and self-organization properties (Chen, Jochems et al. 2018). As mentioned above, human EpCAM+ biliary epithelial cells can be cultivated long term as bipotent organoids in the presence of Forskolin (FSK) for long term, which stimulates Lgr5+ expression (Huch, Gehart et al. 2015). These differentiated into a biliary phenotype through the removal of R-Spondin, nicotinamide, Tgfß1, and FSK from the culture medium. These hBO were used to model aspects of Alagille syndrome, an autosomal dominant disorder of the biliary ducts resulting in cholestasis and biliary injury. Another biliary pathology which has been investigated using BO is ductular reaction (Planas-Paz, Sun et al. 2019). During a ductular reaction, periportal biliary epithelial cells activate in response to biliary injury, and form a transient epithelium. To investigate this process in vitro, mouse EpCAM+ BEC organoids were subject to a CRISPR loss of function screen employing barcoding, and demonstrated that YAP and Wnt pathway was essential for $\mathrm{mBO}$ growth (Planas-Paz, Sun et al. 2019). These pathways were then evaluated in vivo, where YAP, rather than Lgr5, was shown to be heavily involved. Another method to isolate biliary stem cells is through culturing from the bile, which was obtained by endoscopic retrograde cholangiopancreatography (ERCP). A total of $2-5 \mathrm{ml}$ of bile was collected from the mid-portion of the common bile duct, and after filtration and centrifugation, cells were re-suspended in MG and plated in 24-well plates with ADF medium (30\% Wnt conditioned medium, 20\% R-spondin conditioned medium, N2, B27, nicotinamide, noggin, EGF, 
HGF, FGF, ROCK inhibitor, A83-01, and Forskolin). Patient-specific hBO were present after 3-5 days of culture, passaged every 7-10 days. The hBO-expressed biliary epithelial markers, as well as EPCAM, Lgr5, but not hepatocyte markers, and less CFTR, secretin receptor, aquaporin 1, and FGF19 expression compared to control hepatic and bile duct scraped hBO. Bile-derived hBO from patients with primary schlerosing cholangitis (PSC) compared to bile-derived hBO, and discovered notable and significant differences between the two populations, in particular regarding the inflammatory cytokine (Soroka, Assis et al. 2019). hBOs have been recently used in several disease modeling applications which is outside the scope of this review, including biliary strictures and cholangiocarcinoma.

Human PSCs can self-renew and differentiate into diverse cell types are a robust alternative to generate cholangiocytes. Numerous studies have generated cholangiocytes in vitro (Figure 5). Recent studies have generated 3D organoids that appear to be structurally and functionally similar to in vivo ducts. Monolayers of hPSC-derived cholangiocyte-like cells, which normally can't be cultivated in vitro, were recently well characterized with respect to gene and protein expression (Dianat, Dubois-Pot-Schneider et al. 2014). These studies employ a 7-day culture in a 3D matrix and generation of cystic or duct-like structures which were organoids, not due to their cellularity, but due to the fact they mimic in vivo microstructure. These organoids exhibited apico-basal polarity in some instances, and function as measured by multidrug resistance protein 1 (MDR1) function, and bile salt transport. However, it was not clear if the organoids were of intrahepatic (small) cholangiocytes origin expressing (CK7, CK19, NCAM, CFTR and AQP1) or extrahepatic (large) cholangiocytes origin expressing (SCTR, GGT1, TGR5, and AE2). In another hPSC cholangiocyte study (Ogawa, Ogawa et al. 2015), hepatoblasts, the precursors to cholangiocytes, were co-cultured with supporting cells (mouse OP9 stromal cells), and transferred to form hBOs after 2 weeks of culture. The organoids included both duct-like and cystic-like structures, and Notch signaling was shown to be key for differentiation as reported elsewhere (De Assuncao, Sun et al. 2015). Overall, hBOs can be generated to form personalized, self-renewable, and functional 3D organoid structures, but there was high extent of variability between samples, more functional analysis can be done, and these studies do not distinguish between intra- and extrahepatic cholangiocytes.

\section{Pancreatic organoids}

\section{Endocrine pancreatic organoids from primary tissue}

There are several common threads between the hepatobiliary system and the pancreatic system: 1) they play roles in digestion, exocrine functions, endocrine functions, and metabolism, 2) exist in epithelial states with complex cellular functions, and 3) share a group of differentiation specific transcription factors which enables trans-differentiation between these states (Horb, Shen et al. 2003). Furthermore, these organs are biomechanically soft (Desai, Tung et al. 2016; Nagy, de la Zerda et al. 2018). The pancreas is 
significantly smaller (16 times less weight) than the liver in humans, and less demarcated than the liver. The pancreas is composed of three primary tissue components: endocrine, ductal, and acinar cells, each with specific and critical physiological functions. However, human pancreatic cells have been challenging to culture, and 3D interactions are critical, particularly for the pancreatic islet, and donor cells for scarce. Therefore, pancreatic organoids (PO), which we discuss in detail below, were developed in the early 1980s. In these studies, isolated islet cells were embedded primary rat endocrine islet in a collagen matrix (Montesano, Mouron et al. 1983), and the cells self-organized. With this rich history of 3D culture, we will summarize recent work in this area and the key aspects limiting hPO technology.

Primary $\beta$-cell replacement therapies offer an intriguing and promising option for disease reversal, but these complex epithelial cells were traditionally challenging to isolate, culture, and transplant. Nonetheless, scientists and tissue engineers continued to refine islet cell isolation techniques. Primary hPO containing 8-11 weeks old human fetal tissue fragments in 3D MG culture (Bonfanti, Nobecourt et al. 2015) were engineered. Amazingly, the primary epithelial tissue fragments formed budding cyst-like selfassembled within 48 hours, which resemble the acinar/ductal microstructure of the pancreas and could be maintained as long as 5 months. Interestingly, when cultured in the absence of EGF for long term, the organoids expressed endocrine markers such as insulin, glucagon, and somatostatin, and increased, Nkx6.1, the $\beta$-cell marker. Fetal pancreatic tissues have donor limitation, but some proliferative capacity. Fortunately, human adult pancreas biopsies, $1 \mathrm{~cm} 2$ of pancreatic tissue, were isolated into single cells, cultured in MG with growth factors to generate hPO (Hu, Gehart et al. 2018). In summary, fetal or adultderived organoids can be cultivated long term and give rise to endocrine lineages. However, $\beta$-cell maturity, functional analysis, and in vivo fate within organoids or derived from organoids was not explored in these studies, the organoids are heterogeneous, and the actual cell subtype that gives rise to $\beta$-cells within the PO is unclear.

\section{Endocrine hPO from hPSC}

Human PSCs have several advantages discussed above (Figure 6). PO were engineered after 22 days of maturation in 3D culture, which demonstrated markers for endocrine cells, but these were less than in adult pancreatic tissue, and insulin secretion was 100 times lower (Wang, Jin et al. 2017). Another study of 3D hPSC demonstrated endocrine markers in culture and formed PO 50-150 $\mu \mathrm{m}$ in size, similar to physiologic islet size, and when matured and transplanted in a diabetic mouse model, they normalized glucose levels prior to graft loss at 12 days (Kim, Kim et al. 2016). However, these cells lacked glucagon expressing cells. These studies point out that formation of hPO culture at later stages may improve pancreatic endocrine maturation. A key point is that the pancreatic islet contains many cell types, including supporting cell types like endothelial cells. Using this approach, a new hydrogel, termed Amikagel, was 
engineered upon which hPSC-derived pancreatic progenitors were co-cultured with HUVECs to form hPO (Candiello, Grandhi et al. 2018). Amikagel is a polymer hydrogel composed of Amikacin and the crosslinker poly (ethylene glycol) diglycidyl ether (PEGDE). In Amikagel, these hPO demonstrated elevated expression of Pdx1, and insulin when and an increase in secreted C-peptide compared to 2D co-culture. These studies highlight several utilizing hPSC-PO that bear mature beta cells or islet cells some success upon transplantation.

\section{Ductal/Acinar hPO from primary tissue}

Primary tissue samples have been used to engineer PO that model both normal pancreatic ducts and ductal carcinoma. The normal organoids could only be passaged about 20 times, while the tumor-derived organoids could be passaged indefinitely, while expressed ductal markers and exhibited expected oncogenic mutations (Boj, Hwang et al. 2015). Importantly, when these ductal PO were transplanted in vivo, they developed pre-cancerous lesions with abnormal nuclei, which progressed to cancer, as they do in patients. This illustrates the unique ability of ductal PO for disease modeling by recreating the in vivo, epithelial environment (Boj, Hwang et al. 2015). Another study focused on engineering PO by using primary tissue sources in combination with co-culture with cancer-associated fibroblasts (Tsai, McOlash et al. 2018) to generate what we term mixed ductal PO. T-lymphocytes were added in suspension on top of the mixed ductal PO embedded in MG, and migrated towards the organoid. Interestingly mixed ductal PO showed an increase in resistance to gemcitabine treatment when compared to controls. Overall, this innovative study showed modeling tumor architecture/composition can recreate cancer phenotypes (Tsai, McOlash et al. 2018).

\section{Ductal/acinar PO from hPSC}

Human PSC-derived pancreatic acinar/ductal organoids offer new opportunities for disease modeling, since controlled, conditional gene modifications/editing can be performed during differentiation (Figure 6). hPSC-derived hPO, composed primarily of pancreatic progenitor cells, could be differentiated along both the acinar and ductal lineages in vitro (Huang, Holtzinger et al. 2015). 15 weeks after transplantation in mice, organoids demonstrated acinar CPA1+ and ductal (KRT10+)-like structures, resembling the fetal pancreas. When manipulating the genome with oncogenes KRASG12V or TP53R175H, these hPSC- PO demonstrated disorganized architecture similar to a tumor-derived ductal PO. In addition to tumor modeling, human PSC-derived PO have also been used to model pancreatic complications of cystic fibrosis which includes mucus plugging of pancreatic ducts, disrupting pancreatic physiology (Constantinescu, Gleizes et al. 2014). In another study, in CF patient-specific iPSCs, CFTR was activated following organoid formation (Hohwieler, Illing et al. 2017), and CFTR-bearing hPO displayed physical and chemical 
alterations, but can differentiate normally. These studies together demonstrate how hPSC-derived PO are an extremely powerful tool for understanding both congenital diseases and cancer.

\section{Summary and outlook for Part 2}

As we have reviewed here, organoid engineering is an active area of recent research with a wide range of applications, ranging from disease modeling, drug discovery, cell cultivation, and cell therapy. While scientists and engineers have used 3D cultures for over 30 years, organoids represent a subtle difference, which we detail here.

The strengths of organoid cultures, particularly the ones discussed here, are: 1) they can be serially passaged, even when derived from adult tissues, and therefore in part address donor tissue problems, 2) they can contain multiple cell types from an organ of interest, 3) they self-organize to form structural units within the target organ, 4) they can be used to mimic organ development and disease, and 5) they can be used for in vivo therapies. One limitation is that MG is still used in most cases of organoid formation.

Further, despite the milestones achieved by hHO, scientists have not demonstrated the development of hepatic sinusoids from hPSC-derived HO. hBO appear to give rise in many studies to duct-like structures, however, heterogeneity in size, shape, and composition is still an issue. Finally, the cell composition of the hPSC-hPO islet cell types and islet microstructure needs to better mimic intact islets.

Challenges that still remain in engineering organoids include: 1) Analysis and understanding organoid fate upon in vivo transplantation and associated in vivo functions, 2) Improved modeling of organ micro-architecture, 3) Understanding of the multiple cell types within an organoid and what they do, 4) understanding the role of supporting cells versus parenchymal cells, 5) The development of fully personalized organoids in which all cell types are hPSC-derived, 6) The ideal micro-environmental, extracellular matrix (stiffness, composition), and medium conditions are not well understood, 7) Poor understanding of the role of cell metabolism in organoid function, and 8) Lack of use of techniques like bioprocess engineering, encapsulation, materials science (scaffolds), microfabrication, and bioreactors, 9) Lack of understanding of the physics of self-assembly, self-organization, and compaction. Overall, organoids are a versatile and powerful tool that has great potential for wide areas of biological engineering, biology, and medicine.

\section{Part 3:}

The use of organoids has generated an interest in noninvasive assessment of their structure and function. Further, organoids may have a unique ability to repopulate tissue due to their improved epithelial state. Here we review organoid imaging approaches and organoid transplantation data. 


\section{Noninvasive imaging of organoids}

Noninvasive imaging is an important tool in regenerative medicine for interrogating tissues (Willadsen, Chaise et al. 2018) and specifically, organoid imaging has recently been reviewed (Rios and Clevers 2018; Walsh, Cook et al. 2017). Noninvasive imaging enables the assessment of biological processes without tissue fixation/destruction, such that each subject can serve as its own control, and biological pathways are intact. Since embryogenesis and organogenesis involves spatial cellular communication and tissue dynamics (Lancaster, Renner et al. 2013; McCracken, Cata et al. 2014; Rios and Clevers 2018), and organoids can recapitulate these processes, the noninvasive imaging of intact organoids can provide insights to the morphogenesis, cellular differentiation and division, and organoid structure, function and metabolism. Further, it can be used to identify molecular targets in disease modeling and drug screening. Organoid imaging requires an understanding of 1) basic physical principles of interaction of light/radiation with matter, 2) imaging modalities, 3) mechanisms of imaging contrast (transmitted, absorbance, reflectance, fluorescent, proton, nuclear), and 4) methods of generating imaging signal and/or contrast. Normally, noninvasive assessment of in vivo tissues is challenging, because of the absorption and scattering of light, which hinders deep tissue imaging. However, organoids model in vivo tissues, but are miniature enough to enable high spatial resolution imaging. A further advantage of organoids is that they support stem cell and progenitor culture and their cell-cell interactions, which traditional 2D culture does not. Further, organoids provide one of the best models for the analysis of epithelial cell cultures. Thus, combining imaging and organoids has many potential applications.

The most basic approach to organoid imaging is conventional epi-illumination microscopy, which can provide images of the outlines of organoids and some cellular features. The use of fluorescent cells, either through dye-labeling or reporter gene expression, with fluorescence microscopy, provides increased spatial resolution but limited depth resolution $(\sim 150 \mu \mathrm{m})$, since organoids can be in the range of $\sim 500 \mu \mathrm{m}$ to $1 \mathrm{~mm}$ in size. Therefore, multiphoton microscopy, which can greatly increase depth resolution, would be the imaging approach of choice for high resolution imaging of fluorescent cells within single organoids (Nakano, Ando et al. 2012). In vitro fluorescent imaging has been performed with reporter gene imaging of differentiation-specific promoters. For example, two fluorescent reporters were utilized that expressed mCherry and GFP upon activation of Kruppel-like factor 5 (KLF5) and intestine specific homeobox (ISX), respectively. This approach has been used to perform in vitro fluorescence reporter gene imaging of hPSCderived human intestinal organoid (hIO) markers (Jung, Lee et al. 2018) and ex vivo reporter gene imaging within the kidney capsule. Further, fluorescence time lapse reporter-based imaging has been used to track chromosome instability and aberrant cell divisions (chromosome segregation) within human colon cancer organoids (Bolhaqueiro, Ponsioen et al. 2019). A recent comprehensive study employed several imaging studies and compared them to traditional techniques for hPSC-derived retinal organoids (Browne, Arnesano 
et al. 2017). These studies employed several important techniques listed here. Optical coherence tomography (OCT), which employs a coherent, near infrared light, an interferometer, and measures reflected scattering of light within the samples. This technique can be used for high spatial resolution (submicron) imaging of epithelial layers similar to histological analysis. Hyperspectral (HSpec) imaging quantifies autofluorescence at specific emission wavelengths at all points in a sample. Fluorescence lifetime imaging microscopy (FLIM) which uses the decay rate of fluorescence compared to controls rather than levels of emission of specific fluorophores. Finally, micro-computed tomography (microCT) uses X-rays for tomographic imaging based on levels of transmitted photons. In this study, retinal layers could be delineated by OCT, FLIM, and HSpec. Further, FLIM of the optical redox ratio (the fluorescence intensity of NADH divided by the fluorescence intensity of FAD), as well as both the NADH and FAD fluorescence lifetimes, the drug response of breast cancer organoids of varying subtypes was determined in organoids. Responsiveness of organoids was measured in 24 hours, and correlated with tumor xenografts in vivo (Walsh, Cook et al. 2014). These studies together indicate the importance and versatility of noninvasive organoid imaging.

\section{Hepatobiliary and pancreatic organoid transplantation}

Cell transplantation of epithelial tissues for diseases is challenging, since cell harvest removes epithelial cells from their native environment. Transplanted cells need likely compete for nutrition, engraft, migrate, identify local niches where they can survive, and integrate with other epithelial cells, after which they likely start to function. In theory, organoid transplantation can result in improved results compared to traditional cell transplantation, because cells are in their native epithelial state, they may be more likely to survive and integrate compared to 2D monolayer cultures of cells. We begin this discussion of organoid transplantation by reviewing recent studies employing intestinal organoids. Both intestinal and colonic organoids have been transplanted within the kidney capsule, a common, highly vascularized site for stem cell transplantation. hIO transplants demonstrate viability at 1 week (Jung, Lee et al. 2018), and both hIO and colonic (hCO) organoids survived under the kidney capsule of immunodeficient mice for 8-10 weeks (Munera and Wells 2017). hIO and hCO demonstrated increased maturation as judged by RNA-seq, multilineage differentiation, and formation and mimicking of mature organ histoarchitecture (Munera and Wells 2017). Further, genetically edited hPSC were engineered into hCO, transplanted orthotopically for 8-12 weeks into the colon mucosa, without the need for injury \{Roper, 2017 \#683\} and demonstrated premalignant, malignant, and metastatic stages. These studies demonstrate the value of this approach, and that in vivo maturation is a key concept in organoid transplantation.

The liver and pancreatic studies are different because these are solid organs versus hollow organs. We have summarized existing organoid transplantation studies in Table 1. hHO have shown promise for 
development as a direct tissue replacement therapy for patients with end-stage liver disease through studies in animal models (Takebe, Sekine et al. 2013; Collin de l'Hortet, Takeishi et al. 2019). hHO have resulted in mixed results in in transplantation models, with varying models, and efficient methods to transplant hHO orthotopically are still being evaluated (Zhou, Lolas et al. 2017). Although hepatocytes are traditionally transplanted via spleen or portal vein, (Baccarani, Adani et al. 2005), HO were transplanted within the hepatectomy site, but despite local engraftment, long term stability was limited (Zhou, Lolas et al. 2017). In this study, combining hepatocytes with hepatic stellate cells into organoids did not significantly improve the engraftment compared with hepatocytes alone (Zhou, Lolas et al. 2017). These intrahepatic hHO underwent tissue necrosis, and a foreign body-like inflammatory response. Scientists have showed that after gross liver damage, during liver regeneration, macrophages secrete IL6 to promote hepatocyte regeneration. Using this, scientists greatly augmented mouse hepatocyte organoid culture with IL6, followed by intrasplenic organoid transplantation in the Fah -/- model. Amazingly, although the number of mice was low, they reported $80 \%$ repopulation, which was much higher than the $0.1-1 \%$ reported in the CCl4stimulated Lgr5+ organoids after transplantation in the same animal model (Huch, Dorrell et al. 2013; Peng, Logan et al. 2018).

A recent study generated compact hPSC-derived hHO with mixed, uncharacterized mesenchymal and epithelial elements. Interestingly, these aggregates demonstrated spatial patterning, with mesenchyme inside and hepatic cells outside. The hPSC-derived spheroids formed via self-aggregation from an agarose mold and could remain stable for up to one year in vitro. These organoids were evaluated in immunedeficient (Rag2-/- and Il2rg-/-) animals in acute models of liver injury (50\% partial hepatectomy) followed by intraperitoneal transplantation of $2 \times 106$ spheroids and analyzed after 4 weeks. These transplanted mice recovered weight faster than controls, demonstrated albumin secretion, and reduced signs of liver injury. These studies also employed subcutaneous implants of day 15 spheroids cultured on electrospun scaffolds. 3D hepatocytes in biomatrix scaffolds in immune-normal, fumarylacetate hydrolase deficient (Fah-/-) and immune-deficient, (Fah-/-, Rag2-/- and I12rg-/-) animals on the NOD-strain background (FRGN). Subcutaneous transplantation was performed and evaluated after subcutaneous transplantation and NTBC withdrawal, which induces tyrosinemia and liver failure. Studies demonstrated vascularized transplants when compared to controls, demonstrating evidence of liver protein secretion and reduced injury markers (Rashidi, Luu et al. 2018). Takebe et al. utilized a similar culture technique with a self-organizing organoid with hPSC-hep progenitors, MSCs, and HUVECs that are transplanted in the renal capsule. These organoids are able to reverse drug-induced lethal liver failure (Takebe, Sekine et al. 2013; Takebe, Sekine et al. 2017). Overall, studies in hHO transplantation, with improved organoid and transplantation techniques, as well as a deeper understanding of host factors, may become a viable approach to generating large numbers of exogenous hepatocytes and model human disease. 
Several studies have developed hPSC-derived cholangiocytes-like cells and engineered them into thin, single-cell layered organoids (Ogawa, Ogawa et al. 2015; Sampaziotis, de Brito et al. 2017). In a landmark study, biliary epithelial cells were scraped from human extrahepatic biliary ducts, and using similar methods for organoid engineering, they creating cyst-like organoids (Sampaziotis, Justin et al. 2017). These hBO were cultivated on polyglycolic acid (PGA)-based biodegradable scaffolds used for biliary surgery reconstruction by transplanting into the gall bladder wall of immunodeficient mice. Compared to negative controls, the mice with hBO-based scaffolds regenerated the gall bladder wall expressing biliary markers CK7 and CK19 and survived over 100 days. Further, the common bile duct was ligated and repaired using a collagen-based tubular scaffold seeded with $\mathrm{hBO}$. These studies highlight the potential for therapeutic intervention of biliary diseases with $\mathrm{hBO}$ and point towards the use of degradable scaffolds for reconstructing epithelial tissues with native stiffness (Sampaziotis, Justin et al. 2017).

hPSC-derived pancreatic organoids (hPO) are more complex than hHO or hBO because of plethora of cells that arise during pancreas differentiation. hPO-derived pancreatic progenitor cells in monolayer were incorporated into organoids by day 18 and passaged for long term organoid culture every 10-14 days (Hohwieler, Illing et al. 2017). These hPO and patient-specific cystic fibrosis-derived hPO were orthotopically transplanted in mice and evaluated after 5 weeks. Interestingly, these hPO integrated into the donor tissue and maintained their phenotypes (Hohwieler, Illing et al. 2017). In another study, organoids were engineered via co-culture of three separate cell types (Soltanian, Ghezelayagh et al. 2018). Both hPSCderived endothelial cells (EC) and hPSC-derived mesenchymal stem cells (MSC) were established and cocultured with hPSC-derived pancreatic progenitors on growth factor reduced MG to generated hPO. Next, hPO were then placed in a miniature 3D-printed basket-like device and transplanted into the peritoneum of nude mice. Analysis after 90-days showed that hPO within devices exhibited higher levels of vascularization, the number of insulin + cells, and serum C-peptide levels when compared to hPO only transplants (Soltanian, Ghezelayagh et al. 2019). Instead of using stem cell-derived cells, another approach was to engineer hPO composed of HUVECs, MSCs, and human islets and transplant these under the renal capsule of immune-deficient mice (Takahashi, Sekine et al. 2018). These studies showed elevated levels of human insulin compared to islets alone. Further, in a cranial window model, these mixed hPO showed earlier times than islets alone (Takahashi, Sekine et al. 2018). These studies suggest vascularization after organoid transplantation may lead to more successful engraftment. Another important avenue for hPO studies are those that involve cancer. PO studies were employed with OncoVee ${ }^{\mathrm{TM}}$-Mini PDX assay system, which bears hollow fibers. Primary tumors were digested purified, and loaded into these fiber-based capsules and transplanted in mice to form hPO in vivo (Zhang, Wang et al. 2018). Analysis of tumor growth in response to drugs was similar to more complex patient-derived xenografts, suggesting this system could 
be widely used. Taken together, these studies demonstrate how transplantation of hepatic, biliary, and pancreatic organoids are being evaluated and the general positive results that have been achieved.

\section{Summary and outlook for Part 3}

We review two major topics in organoid technology, organoid imaging and transplantation. Organoid imaging is an active area of research that can answer major questions about organoids, including morphogenesis, size, growth, epithelial states, cell-cell interactions, and metabolism. Reporter gene imaging has been used for imaging differentiation, cell division, and many other processes in organoids, label-free imaging has been powerful approach. We expect organoid imaging to further develop, particularly with applications in high throughput, screening approaches and in disease modeling applications in which biomarkers can be evaluated. Organoid transplantation has been successful approach since epithelial state is preserved, and both intact organoids and organoids that have been dissociated have provided extremely exciting data in the area of hepatobiliary and pancreatic organoid transplantation. For liver and pancreatic cell therapies, major issues are mass of cells and functions, whereas for biliary cell therapies major issues include structural integrity. Reported success in animal models bode well for continued translation of organoid technology towards patients with hepatobiliary and pancreatic diseases.

\section{Conclusions}

(1) Organoids have emerged as a system for recapitulating the composition, epithelial structure, and cellular heterogeneity observed in primary tissues.

(2) The studies reviewed here demonstrated several principles of organoid culture, including the use of progenitors, spatial segregation and aggregation, morphogenesis, and maturation.

(3) Foundational investigations of cell biology using cell lines cultured in $2 \mathrm{D}$ and/or mouse models do not capture the essential biological and biomechanical features of their in vivo counterparts.

(4) Organoids have been used in several research areas including cellular regeneration, organ development, disease modelling, and tissue maintenance.

(5) Several efforts are aimed towards designing complex tissue from organoids which can mimic the native architecture of organs. However, to form complex tissues, there will be a requirement for advanced tissue engineering techniques will be required to control organoid shape and composition.

(6) A major research focus is on the capacity of organoids to regenerate tissue following transplantation.

(7) Cell maturation within organoids will need to improve in order to develop effective disease and tissue models. One avenue to improve maturation may be to improve the state of the progenitor cell cultures prior to the formation of organoids. 
(8) The challenges above, if overcome, can rapidly advance our understanding of many biological mechanisms.

(9) Organoids are a robust cell culture technique that, despite limitations, can serve as a useful tool to study human organs.

TABLE 1. Summary of hepatic, biliary, and pancreatic organoid transplantation

\begin{tabular}{|c|c|c|c|c|}
\hline Author & $\begin{array}{l}\text { Organoid } \\
\text { type }\end{array}$ & $\begin{array}{l}\text { Type of } \\
\text { organoid } \\
\text { transplant }\end{array}$ & Summary Finding & Application \\
\hline $\begin{array}{l}\text { (Rashidi, Luu et al. } \\
\text { 2018) }\end{array}$ & Hepatic & Non-orthotopic & $\begin{array}{l}\text { Maintenance of PSC-derived } \\
\text { hepatospheres for up } 1 \text { year in vitro }\end{array}$ & $\begin{array}{l}\text { Reversal of acute liver failure. } \\
\text { Liver development studies, long } \\
\text { term drug toxicity studies }\end{array}$ \\
\hline (Nie, Zheng et al. 2018) & Hepatic & Non-orthotopic & $\begin{array}{l}\text { Model of HBV infection in hPSC- } \\
\text { liver organoids can mimic virus } \\
\text { life cycle }\end{array}$ & $\begin{array}{l}\text { Infection model for personalized } \\
\text { treatment of hepatitis }\end{array}$ \\
\hline $\begin{array}{l}\text { (Sampaziotis, Justin et } \\
\text { al. 2017) }\end{array}$ & Biliary & Non-orthotopic & $\begin{array}{l}\text { hPSC-derived cholangiocytes } \\
\text { exhibit functional and } \\
\text { morphological features of in vivo } \\
\text { biliary cells }\end{array}$ & $\begin{array}{l}\text { Disease modelling of } \\
\text { cholangiopathies and screening of } \\
\text { therapeutic compounds }\end{array}$ \\
\hline $\begin{array}{l}\text { (Ng, Saeb-Parsy et al. } \\
\text { 2018) }\end{array}$ & Hepatic & Non-orthotopic & $\begin{array}{l}\text { hPSC-derived liver organoids } \\
\text { encapsulated in engineered colloid } \\
\text { crystal matrix exhibit enhanced } \\
\text { liver-like properties }\end{array}$ & $\begin{array}{l}\text { Fully defined liver organoid } \\
\text { platform for disease modelling } \\
\text { and drug developmental studies }\end{array}$ \\
\hline (Hu, Gehart et al. 2018) & Hepatic & Non-orthotopic & $\begin{array}{l}\text { Single cell expansion of mouse and } \\
\text { human hepatocytes in organoid } \\
\text { culture }\end{array}$ & $\begin{array}{l}\text { Cell reservoir for applications in } \\
\text { drug development, disease } \\
\text { modelling and cell therapy }\end{array}$ \\
\hline $\begin{array}{l}\text { (Peng, Logan et al. } \\
\text { 2018) }\end{array}$ & Hepatic & Non-orthotopic & $\begin{array}{l}\text { TNF } \alpha \text { promotes in-vitro mouse } \\
\text { hepatocyte expansion - more than } \\
6 \text { months }\end{array}$ & $\begin{array}{l}\text { Cell reservoir for applications in } \\
\text { drug development, disease } \\
\text { modelling and cell therapy }\end{array}$ \\
\hline $\begin{array}{l}\text { (Zhang, Zheng et al. } \\
\text { 2018) }\end{array}$ & Hepatic & Non-orthotopic & $\begin{array}{l}\text { Hepatic stem cells isolated from } \\
\text { fetal liver tissues via CSCP1+ } \\
\text { CD90+ CD66- antibodies }\end{array}$ & Liver regeneration studies \\
\hline
\end{tabular}




\begin{tabular}{|c|c|c|c|c|}
\hline $\begin{array}{l}\text { (Zhou, Lolas et al. } \\
\text { 2017) }\end{array}$ & Hepatic & Orthotopic & $\begin{array}{l}\text { Transplantation of bioreactor } \\
\text { derived hepatic organoids into } \\
\text { mouse models of hepatectomy do } \\
\text { not form new tissue }\end{array}$ & $\begin{array}{l}\text { Generation of hepatic tissue after } \\
\text { hepatectomy }\end{array}$ \\
\hline $\begin{array}{l}\text { (Takebe, Sekine et al. } \\
\text { 2017) }\end{array}$ & Hepatic & Non-orthotopic & $\begin{array}{l}\text { hPSC organ bud formation and } \\
\text { vascularization from intermixed } \\
\text { iPSC derived liver progenitor cells }\end{array}$ & $\begin{array}{l}\text { Experimental foundation for } \\
\text { studies in drug development, } \\
\text { disease modelling and cell } \\
\text { therapy }\end{array}$ \\
\hline $\begin{array}{l}\text { (Huch, Gehart et al. } \\
\text { 2015) }\end{array}$ & Hepatic & Non-orthotopic & $\begin{array}{l}\text { Bipotent adult liver stem cells can } \\
\text { be expanded over an extended time } \\
\text { period }\end{array}$ & $\begin{array}{l}\text { Experimental foundation for } \\
\text { studies in drug development, } \\
\text { disease modelling and cell } \\
\text { therapy }\end{array}$ \\
\hline $\begin{array}{l}\text { (Huch, Dorrell et al. } \\
\text { 2013) }\end{array}$ & Hepatic & Non-orthotopic & $\begin{array}{l}\text { Lgr5+ liver stem cells repopulate } \\
\text { liver after acute injury }\end{array}$ & $\begin{array}{l}\text { Organ regeneration via stem cell } \\
\text { repopulation }\end{array}$ \\
\hline $\begin{array}{l}\text { (Knight, Kerman et al. } \\
\text { 2006) }\end{array}$ & Pancreatic & Orthotopic & $\begin{array}{l}\text { Application of post-transplant } \\
\text { immunosuppressive drugs } \\
\text { (thymoglobulin, sirolimus and } \\
\text { cyclosporine) on patients receiving } \\
\text { pancreas transplant enhances } \\
\text { survival outcome }\end{array}$ & $\begin{array}{l}\text { Survival and function of } \\
\text { transplanted islets to improve } \\
\text { glycemic control }\end{array}$ \\
\hline $\begin{array}{l}\text { (Soltanian, } \\
\text { Ghezelayagh et al. } \\
\text { 2018) }\end{array}$ & Pancreatic & Non-orthotopic & $\begin{array}{l}\text { hPSC-derived pancreatic organoids } \\
\text { transplanted peritoneally exhibit } \\
\text { enhanced vascularization, insulin }+ \\
\text { cells }\end{array}$ & $\begin{array}{l}\text { Generation of mature pancreatic } \\
\text { tissue, novel therapeutics, and } \\
\text { diabetic regenerative therapies }\end{array}$ \\
\hline $\begin{array}{l}\text { (Zhang, Wang et al. } \\
\text { 2018) }\end{array}$ & Pancreatic & Non-orthotopic & $\begin{array}{l}\text { In vivo drug sensitivity assay } \\
\text { OncoVee demonstrates high } \\
\text { sensitivity and specificity towards } \\
\text { patient derived tumor samples }\end{array}$ & $\begin{array}{l}\text { Characterization of patient } \\
\text { derived xenografts for clinical } \\
\text { trial }\end{array}$ \\
\hline $\begin{array}{l}\text { (Takahashi, Sekine et } \\
\text { al. 2018) }\end{array}$ & Pancreatic & Non-orthotopic & $\begin{array}{l}\text { hPSC-derived organoids can } \\
\text { minimize diabetes in mouse } \\
\text { disease model }\end{array}$ & $\begin{array}{l}\text { In vivo tissue transplantation } \\
\text { therapy }\end{array}$ \\
\hline (Kim, Kim et al. 2016) & Pancreatic & Non-orthotopic & $\begin{array}{l}\text { Aldehyde dehydrogenase } 1 \mathrm{a} 3 \\
\text { identifies a subset of failing beta } \\
\text { cells in diabetic mice }\end{array}$ & $\begin{array}{l}\text { Restoration of glucose level in } \\
\text { vivo }\end{array}$ \\
\hline $\begin{array}{l}\text { (Raikwar, Kim et al. } \\
\text { 2015) }\end{array}$ & Pancreatic & Non-orthotopic & $\begin{array}{l}\text { hPSC-derived beta cells form } \\
\text { vascularized insulin secreting } \\
\text { tissues upon in vivo transplantation }\end{array}$ & Production of insulin in vivo \\
\hline
\end{tabular}




\begin{tabular}{|l|l|l|l|l|}
\hline $\begin{array}{l}\text { (Boj, Hwang et al. } \\
\text { 2015) }\end{array}$ & Pancreatic & Orthotopic & $\begin{array}{l}\text { Orthotopically transplanted } \\
\text { neoplastic organoids recapitulate } \\
\text { tumor development }\end{array}$ & $\begin{array}{l}\text { Organoid model of tumor } \\
\text { malignancy }\end{array}$ \\
\hline
\end{tabular}

\section{Conflict of interest}

NP is founder of a biotechnology company, Livandala, that aims to use stem cells to treat liver disease. Other than this, the authors declare no conflicting interests in the subject content discussed in this manuscript.

\section{AUTHOR CONTRIBUTIONS:}

OO: Wrote, edited, and approved manuscript.

MM: Wrote, edited, and approved manuscript.

NP: Wrote, edited, supervised, and approved manuscript.

\section{References}

Asai, A., E. Aihara, C. Watson, R. Mourya, T. Mizuochi, P. Shivakumar, K. Phelan, C. Mayhew, M. Helmrath, T. Takebe, J. Wells and J. A. Bezerra (2017). "Paracrine signals regulate human liver organoid maturation from induced pluripotent stem cells." Development 144(6): 1056-1064.

Baccarani, U., G. L. Adani, M. Sainz, A. Donini, A. Risaliti and F. Bresadola (2005). "Human hepatocyte transplantation for acute liver failure: state of the art and analysis of cell sources." Transplant Proc 37(6): 2702-2704.

Bhatia, S. N., U. J. Balis, M. L. Yarmush and M. Toner (1998). "Microfabrication of hepatocyte/fibroblast co-cultures: role of homotypic cell interactions." Biotechnol Prog 14(3): 378-387. Bhogal, R. H. and S. C. Afford (2011). "Anti-oxidants do not prevent bile acid-induced cell death in rat hepatocytes." Liver Int 31(2): 273-274; author reply 274-275.

Bhogal, R. H., J. Hodson, D. C. Bartlett, C. J. Weston, S. M. Curbishley, E. Haughton, K. T. Williams, G. M. Reynolds, P. N. Newsome, D. H. Adams and S. C. Afford (2011). "Isolation of primary human hepatocytes from normal and diseased liver tissue: a one hundred liver experience." PLoS One 6(3): e18222.

Boj, S. F., C.-I. Hwang, L. A. Baker, I. I. C. Chio, D. D. Engle, V. Corbo, M. Jager, M. Ponz-Sarvise, H. Tiriac and M. S. Spector (2015). "Organoid models of human and mouse ductal pancreatic cancer." Cell 160(1): 324-338.

Boj, S. F., C. I. Hwang, L. A. Baker, Chio, II, D. D. Engle, V. Corbo, M. Jager, M. Ponz-Sarvise, H. Tiriac, M. S. Spector, A. Gracanin, T. Oni, K. H. Yu, R. van Boxtel, M. Huch, K. D. Rivera, J. P. Wilson, M. E. Feigin, D. Ohlund, A. Handly-Santana, C. M. Ardito-Abraham, M. Ludwig, E. Elyada, B. Alagesan, G. Biffi, G. N. Yordanov, B. Delcuze, B. Creighton, K. Wright, Y. Park, F. H. Morsink, I. Q. Molenaar, I. H. Borel Rinkes, E. Cuppen, Y. Hao, Y. Jin, I. J. Nijman, C. Iacobuzio-Donahue, S. D. Leach, D. J. Pappin, M. Hammell, D. S. Klimstra, O. Basturk, R. H. Hruban, G. J. Offerhaus, R. G. Vries, 
H. Clevers and D. A. Tuveson (2015). "Organoid models of human and mouse ductal pancreatic cancer." Cell 160(1-2): 324-338.

Bolhaqueiro, A. C. F., B. Ponsioen, B. Bakker, S. J. Klaasen, E. Kucukkose, R. H. van Jaarsveld, J. Vivie, I. Verlaan-Klink, N. Hami, D. C. J. Spierings, N. Sasaki, D. Dutta, S. F. Boj, R. G. J. Vries, P. M. Lansdorp, M. van de Wetering, A. van Oudenaarden, H. Clevers, O. Kranenburg, F. Foijer, H. J. G. Snippert and G. Kops (2019). "Ongoing chromosomal instability and karyotype evolution in human colorectal cancer organoids." Nat Genet 51(5): 824-834.

Bonfanti, P., E. Nobecourt, M. Oshima, O. Albagli-Curiel, V. Laurysens, G. Stange, M. Sojoodi, Y. Heremans, H. Heimberg and R. Scharfmann (2015). "Ex Vivo Expansion and Differentiation of Human and Mouse Fetal Pancreatic Progenitors Are Modulated by Epidermal Growth Factor." Stem Cells Dev 24(15): 1766-1778.

Britten, R. J. and E. H. Davidson (1969). "Gene regulation for higher cells: a theory." Science 165(3891): 349-357.

Browne, A. W., C. Arnesano, N. Harutyunyan, T. Khuu, J. C. Martinez, H. A. Pollack, D. S. Koos, T. C. Lee, S. E. Fraser, R. A. Moats, J. G. Aparicio and D. Cobrinik (2017). "Structural and Functional Characterization of Human Stem-Cell-Derived Retinal Organoids by Live Imaging." Invest Ophthalmol Vis Sci 58(9): 3311-3318.

Burkard, A., C. Dahn, S. Heinz, A. Zutavern, V. Sonntag-Buck, D. Maltman, S. Przyborski, N. J. Hewitt and J. Braspenning (2012). "Generation of proliferating human hepatocytes using Upcyte(R) technology: characterisation and applications in induction and cytotoxicity assays." Xenobiotica 42(10): 939-956. Camp, J. G., F. Badsha, M. Florio, S. Kanton, T. Gerber, M. Wilsch-Brauninger, E. Lewitus, A. Sykes, W. Hevers, M. Lancaster, J. A. Knoblich, R. Lachmann, S. Paabo, W. B. Huttner and B. Treutlein (2015). "Human cerebral organoids recapitulate gene expression programs of fetal neocortex development." Proc Natl Acad Sci U S A 112(51): 15672-15677.

Candiello, J., T. S. P. Grandhi, S. K. Goh, V. Vaidya, M. Lemmon-Kishi, K. R. Eliato, R. Ros, P. N. Kumta, K. Rege and I. Banerjee (2018). "3D heterogeneous islet organoid generation from human embryonic stem cells using a novel engineered hydrogel platform." Biomaterials 177: 27-39.

Cerec, V., D. Glaise, D. Garnier, S. Morosan, B. Turlin, B. Drenou, P. Gripon, D. Kremsdorf, C. GuguenGuillouzo and A. Corlu (2007). "Transdifferentiation of hepatocyte-like cells from the human hepatoma HepaRG cell line through bipotent progenitor." Hepatology 45(4): 957-967.

Chen, C., P. G. M. Jochems, L. Salz, K. Schneeberger, L. C. Penning, S. F. J. van de Graaf, U. Beuers, H. Clevers, N. Geijsen, R. Masereeuw and B. Spee (2018). "Bioengineered bile ducts recapitulate key cholangiocyte functions." Biofabrication 10(3): 034103.

Chen, Q. S., S. Utech, D. Chen, R. Prodanovic, J. M. Lin and D. A. Weitz (2016). "Controlled assembly of heterotypic cells in a core-shell scaffold: organ in a droplet." Lab on a Chip 16(8): 1346-1349.

Cho, C. H., N. Parashurama, E. Y. Park, K. Suganuma, Y. Nahmias, J. Park, A. W. Tilles, F. Berthiaume and M. L. Yarmush (2008). "Homogeneous differentiation of hepatocyte-like cells from embryonic stem cells: applications for the treatment of liver failure." FASEB J 22(3): 898-909.

Coll, M., L. Perea, R. Boon, S. B. Leite, J. Vallverdu, I. Mannaerts, A. Smout, A. El Taghdouini, D. Blaya, D. Rodrigo-Torres, I. Graupera, B. Aguilar-Bravo, C. Chesne, M. Najimi, E. Sokal, J. J. Lozano, L. A. van Grunsven, C. M. Verfaillie and P. Sancho-Bru (2018). "Generation of Hepatic Stellate Cells from Human Pluripotent Stem Cells Enables In Vitro Modeling of Liver Fibrosis." Cell Stem Cell 23(1): 101-113 e107.

Collin de l'Hortet, A., K. Takeishi, J. Guzman-Lepe, K. Morita, A. Achreja, B. Popovic, Y. Wang, K. Handa, A. Mittal, N. Meurs, Z. Zhu, F. Weinberg, M. Salomon, I. J. Fox, C. X. Deng, D. Nagrath and A. Soto-Gutierrez (2019). "Generation of Human Fatty Livers Using Custom-Engineered Induced Pluripotent Stem Cells with Modifiable SIRT1 Metabolism." Cell Metab 30(2): 385-401 e389. Constantinescu, A. A., C. Gleizes, M. Alhosin, E. Yala, F. Zobairi, A. Leclercq, G. Stoian, I. L. Mitrea, G. Prévost and F. Toti (2014). "Exocrine cell-derived microparticles in response to lipopolysaccharide promote endocrine dysfunction in cystic fibrosis." Journal of Cystic Fibrosis 13(2): 219-226. 
Czerniecki, S. M., N. M. Cruz, J. L. Harder, R. Menon, J. Annis, E. A. Otto, R. E. Gulieva, L. V. Islas, Y. K. Kim, L. M. Tran, T. J. Martins, J. W. Pippin, H. Fu, M. Kretzler, S. J. Shankland, J. Himmelfarb, R. T. Moon, N. Paragas and B. S. Freedman (2018). "High-Throughput Screening Enhances Kidney Organoid Differentiation from Human Pluripotent Stem Cells and Enables Automated Multidimensional Phenotyping." Cell Stem Cell 22(6): 929-940 e924.

De Assuncao, T. M., Y. Sun, N. Jalan-Sakrikar, M. C. Drinane, B. Q. Huang, Y. Li, J. I. Davila, R. Wang, S. P. O'Hara, G. A. Lomberk, R. A. Urrutia, Y. Ikeda and R. C. Huebert (2015). "Development and characterization of human-induced pluripotent stem cell-derived cholangiocytes." Lab Invest 95(6): 684696.

Deglincerti, A., F. Etoc, M. Z. Ozair and A. H. Brivanlou (2016). "Self-Organization of Spatial Patterning in Human Embryonic Stem Cells." Curr Top Dev Biol 116: 99-113.

Desai, S. S., J. C. Tung, V. X. Zhou, J. P. Grenert, Y. Malato, M. Rezvani, R. Espanol-Suner, H. Willenbring, V. M. Weaver and T. T. Chang (2016). "Physiological ranges of matrix rigidity modulate primary mouse hepatocyte function in part through hepatocyte nuclear factor 4 alpha." Hepatology 64(1): 261-275.

Dianat, N., H. Dubois-Pot-Schneider, C. Steichen, C. Desterke, P. Leclerc, A. Raveux, L. Combettes, A. Weber, A. Corlu and A. Dubart-Kupperschmitt (2014). "Generation of functional cholangiocyte-like cells from human pluripotent stem cells and HepaRG cells." Hepatology 60(2): 700-714.

Diz-Munoz, A., M. Krieg, M. Bergert, I. Ibarlucea-Benitez, D. J. Muller, E. Paluch and C. P. Heisenberg (2010). "Control of directed cell migration in vivo by membrane-to-cortex attachment." PLoS Biol 8(11): e1000544.

Dorrell, C., L. Erker, K. M. Lanxon-Cookson, S. L. Abraham, T. Victoroff, S. Ro, P. S. Canaday, P. R. Streeter and M. Grompe (2008). "Surface markers for the murine oval cell response." Hepatology 48(4): 1282-1291.

Dorrell, C., B. Tarlow, Y. Wang, P. S. Canaday, A. Haft, J. Schug, P. R. Streeter, M. J. Finegold, L. T. Shenje, K. H. Kaestner and M. Grompe (2014). "The organoid-initiating cells in mouse pancreas and liver are phenotypically and functionally similar." Stem Cell Res 13(2): 275-283.

Duval, K., H. Grover, L. H. Han, Y. Mou, A. F. Pegoraro, J. Fredberg and Z. Chen (2017). "Modeling Physiological Events in 2D vs. 3D Cell Culture." Physiology (Bethesda) 32(4): 266-277.

Eiraku, M., N. Takata, H. Ishibashi, M. Kawada, E. Sakakura, S. Okuda, K. Sekiguchi, T. Adachi and Y. Sasai (2011). "Self-organizing optic-cup morphogenesis in three-dimensional culture." Nature 472(7341): 51-56.

Eiraku, M., K. Watanabe, M. Matsuo-Takasaki, M. Kawada, S. Yonemura, M. Matsumura, T. Wataya, A. Nishiyama, K. Muguruma and Y. Sasai (2008). "Self-organized formation of polarized cortical tissues from ESCs and its active manipulation by extrinsic signals." Cell Stem Cell 3(5): 519-532.

Ellis, C., A. Ramzy and T. J. Kieffer (2017). "Regenerative medicine and cell-based approaches to restore pancreatic function." Nat Rev Gastroenterol Hepatol 14(10): 612-628.

Erickson, C. A., R. P. Tucker and B. F. Edwards (1987). "Changes in the distribution of intermediatefilament types in Japanese quail embryos during morphogenesis." Differentiation 34(2): 88-97.

Ezzell, R. M., W. H. Goldmann, N. Wang, N. Parashurama and D. E. Ingber (1997). "Vinculin promotes cell spreading by mechanically coupling integrins to the cytoskeleton." Exp Cell Res 231(1): 14-26.

Fernekorn, U., J. Hampl, F. Weise, M. Klett, A. Laffert, K. Friedel and A. Schober (2015). "Microfluidic 3D HepG2 cell culture: Reproducing hepatic tumor gene and protein expression in in vitro scaffolds." Engineering in Life Sciences 15(3): 340-350.

Fletcher, A. G., M. Osterfield, R. E. Baker and S. Y. Shvartsman (2014). "Vertex models of epithelial morphogenesis." Biophys J 106(11): 2291-2304.

Gerlach, J. C., P. Over, M. E. Turner, R. L. Thompson, H. G. Foka, W. C. Chen, B. Peault, B. Gridelli and E. Schmelzer (2012). "Perivascular mesenchymal progenitors in human fetal and adult liver." Stem Cells Dev 21(18): 3258-3269. 
Giovannetti, E., V. Mey, R. Danesi, I. Mosca and M. Del Tacca (2004). "Synergistic cytotoxicity and pharmacogenetics of gemcitabine and pemetrexed combination in pancreatic cancer cell lines." Clinical Cancer Research 10(9): 2936-2943.

Glicklis, R., J. C. Merchuk and S. Cohen (2004). "Modeling mass transfer in hepatocyte spheroids via cell viability, spheroid size, and hepatocellular functions." Biotechnol Bioeng 86(6): 672-680.

Gracz, A. D., I. A. Williamson, K. C. Roche, M. J. Johnston, F. Wang, Y. Wang, P. J. Attayek, J. Balowski, X. F. Liu, R. J. Laurenza, L. T. Gaynor, C. E. Sims, J. A. Galanko, L. Li, N. L. Allbritton and S. T. Magness (2015). "A high-throughput platform for stem cell niche co-cultures and downstream gene expression analysis." Nat Cell Biol 17(3): 340-349.

Gridelli, B., G. Vizzini, G. Pietrosi, A. Luca, M. Spada, S. Gruttadauria, D. Cintorino, G. Amico, C. Chinnici, T. Miki, E. Schmelzer, P. G. Conaldi, F. Triolo and J. C. Gerlach (2012). "Efficient human fetal liver cell isolation protocol based on vascular perfusion for liver cell-based therapy and case report on cell transplantation." Liver Transplantation 18(2): 226-237.

Grun, D., A. Lyubimova, L. Kester, K. Wiebrands, O. Basak, N. Sasaki, H. Clevers and A. van Oudenaarden (2015). "Single-cell messenger RNA sequencing reveals rare intestinal cell types." Nature 525(7568): 251-255.

Harrell, J. R. and B. Goldstein (2011). "Internalization of multiple cells during C. elegans gastrulation depends on common cytoskeletal mechanisms but different cell polarity and cell fate regulators." Dev Biol 350(1): 1-12.

Helmlinger, G., P. A. Netti, H. C. Lichtenbeld, R. J. Melder and R. K. Jain (1997). "Solid stress inhibits the growth of multicellular tumor spheroids." Nat Biotechnol 15(8): 778-783.

Hendriks, D. F. G., L. F. Puigvert, S. Messner, W. Mortiz and M. Ingelman-Sundberg (2016). "Hepatic 3D spheroid models for the detection and study of compounds with cholestatic liability." Scientific Reports 6.

Hohwieler, M., A. Illing, P. C. Hermann, T. Mayer, M. Stockmann, L. Perkhofer, T. Eiseler, J. S. Antony, M. Muller, S. Renz, C. C. Kuo, Q. Lin, M. Sendler, M. Breunig, S. M. Kleiderman, A. Lechel, M. Zenker, M. Leichsenring, J. Rosendahl, M. Zenke, B. Sainz, J. Mayerle, I. G. Costa, T. Seufferlein, M. Kormann, M. Wagner, S. Liebau and A. Kleger (2017). "Human pluripotent stem cell-derived acinar/ductal organoids generate human pancreas upon orthotopic transplantation and allow disease modelling." Gut 66(3): 473-486.

Horb, M. E., C. N. Shen, D. Tosh and J. M. Slack (2003). "Experimental conversion of liver to pancreas." Curr Biol 13(2): 105-115.

Hu, H., H. Gehart, B. Artegiani, L. O.-I. C, F. Dekkers, O. Basak, J. van Es, S. M. Chuva de Sousa Lopes, H. Begthel, J. Korving, M. van den Born, C. Zou, C. Quirk, L. Chiriboga, C. M. Rice, S. Ma, A. Rios, P. J. Peters, Y. P. de Jong and H. Clevers (2018). "Long-Term Expansion of Functional Mouse and Human Hepatocytes as 3D Organoids." Cell 175(6): 1591-1606 e1519.

Huang, L., A. Holtzinger, I. Jagan, M. BeGora, I. Lohse, N. Ngai, C. Nostro, R. Wang, L. B. Muthuswamy and H. C. Crawford (2015). "Ductal pancreatic cancer modeling and drug screening using human pluripotent stem cell-and patient-derived tumor organoids." Nature medicine 21(11): 1364-1371. Huch, M., C. Dorrell, S. F. Boj, J. H. van Es, V. S. Li, M. van de Wetering, T. Sato, K. Hamer, N. Sasaki, M. J. Finegold, A. Haft, R. G. Vries, M. Grompe and H. Clevers (2013). "In vitro expansion of single Lgr5+ liver stem cells induced by Wnt-driven regeneration." Nature 494(7436): 247-250.

Huch, M., H. Gehart, R. van Boxtel, K. Hamer, F. Blokzijl, M. M. Verstegen, E. Ellis, M. van Wenum, S. A. Fuchs, J. de Ligt, M. van de Wetering, N. Sasaki, S. J. Boers, H. Kemperman, J. de Jonge, J. N. Ijzermans, E. E. Nieuwenhuis, R. Hoekstra, S. Strom, R. R. Vries, L. J. van der Laan, E. Cuppen and H. Clevers (2015). "Long-term culture of genome-stable bipotent stem cells from adult human liver." Cell 160(1-2): 299-312.

Jung, K. B., H. Lee, Y. S. Son, J. H. Lee, H. S. Cho, M. O. Lee, J. H. Oh, J. Lee, S. Kim, C. R. Jung, J. Kim and M. Y. Son (2018). "In vitro and in vivo imaging and tracking of intestinal organoids from human induced pluripotent stem cells." FASEB J 32(1): 111-122. 
Kim, I., Y. S. Choi, J. H. Song, E. A. Choi, S. Park, E. J. Lee, J. K. Rhee, S. C. Kim and S. Chang (2018). "A drug-repositioning screen for primary pancreatic ductal adenocarcinoma cells identifies 6-thioguanine as an effective therapeutic agent for TPMT-low cancer cells." Mol Oncol 12(9): 1526-1539.

Kim, Y., H. Kim, U. H. Ko, Y. Oh, A. Lim, J.-W. Sohn, J. H. Shin, H. Kim and Y.-M. Han (2016). "Isletlike organoids derived from human pluripotent stem cells efficiently function in the glucose responsiveness in vitro and in vivo." Scientific reports 6: 35145.

Kim, Y., H. Kim, U. H. Ko, Y. Oh, A. Lim, J. W. Sohn, J. H. Shin, H. Kim and Y. M. Han (2016). "Isletlike organoids derived from human pluripotent stem cells efficiently function in the glucose responsiveness in vitro and in vivo." Sci Rep 6: 35145.

Knight, R. J., R. H. Kerman, S. Zela, J. Podbielski, H. Podder, C. T. Van Buren, S. Katz and B. D. Kahan (2006). "Pancreas transplantation utilizing thymoglobulin, sirolimus, and cyclosporine." Transplantation 81(8): 1101-1105.

Lakins, J. N., A. R. Chin and V. M. Weaver (2012). "Exploring the link between human embryonic stem cell organization and fate using tension-calibrated extracellular matrix functionalized polyacrylamide gels." Methods Mol Biol 916: 317-350.

Lancaster, M. A., M. Renner, C. A. Martin, D. Wenzel, L. S. Bicknell, M. E. Hurles, T. Homfray, J. M. Penninger, A. P. Jackson and J. A. Knoblich (2013). "Cerebral organoids model human brain development and microcephaly." Nature 501(7467): 373-379.

Le Bras, S. and R. Le Borgne (2014). "Epithelial cell division - multiplying without losing touch." J Cell Sci 127(Pt 24): 5127-5137.

Levental, K. R., H. Yu, L. Kass, J. N. Lakins, M. Egeblad, J. T. Erler, S. F. Fong, K. Csiszar, A. Giaccia, W. Weninger, M. Yamauchi, D. L. Gasser and V. M. Weaver (2009). "Matrix crosslinking forces tumor progression by enhancing integrin signaling." Cell 139(5): 891-906.

Levy, G., D. Bomze, S. Heinz, S. D. Ramachandran, A. Noerenberg, M. Cohen, O. Shibolet, E. Sklan, J. Braspenning and Y. Nahmias (2015). "Long-term culture and expansion of primary human hepatocytes." Nat Biotechnol 33(12): 1264-1271.

Li, B., C. Dorrell, P. S. Canaday, C. Pelz, A. Haft, M. Finegold and M. Grompe (2017). "Adult Mouse Liver Contains Two Distinct Populations of Cholangiocytes." Stem Cell Reports 9(2): 478-489.

Libby, A. R., D. A. Joy, P. L. So, M. A. Mandegar, J. M. Muncie, F. N. Mendoza-Camacho, V. M. Weaver, B. R. Conklin and T. C. McDevitt (2018). "Spatiotemporal mosaic self-patterning of pluripotent stem cells using CRISPR interference." Elife 7.

Limaye, P. B., W. C. Bowen, A. V. Orr, J. Luo, G. C. Tseng and G. K. Michalopoulos (2008).

"Mechanisms of hepatocyte growth factor-mediated and epidermal growth factor-mediated signaling in transdifferentiation of rat hepatocytes to biliary epithelium." Hepatology 47(5): 1702-1713.

Lin, R. Z., L. F. Chou, C. C. Chien and H. Y. Chang (2006). "Dynamic analysis of hepatoma spheroid formation: roles of E-cadherin and beta1-integrin." Cell Tissue Res 324(3): 411-422.

Luckert, C., C. Schulz, N. Lehmann, M. Thomas, U. Hofmann, S. Hammad, J. G. Hengstler, A. Braeuning, A. Lampen and S. Hessel (2017). "Comparative analysis of 3D culture methods on human HepG2 cells." Arch Toxicol 91(1): 393-406.

Martin, A. C., M. Gelbart, R. Fernandez-Gonzalez, M. Kaschube and E. F. Wieschaus (2010).

"Integration of contractile forces during tissue invagination." J Cell Biol 188(5): 735-749.

McCracken, K. W., E. M. Cata, C. M. Crawford, K. L. Sinagoga, M. Schumacher, B. E. Rockich, Y. H. Tsai, C. N. Mayhew, J. R. Spence, Y. Zavros and J. M. Wells (2014). "Modelling human development and disease in pluripotent stem-cell-derived gastric organoids." Nature 516(7531): 400-404.

Michalopoulos, G. K., W. C. Bowen, K. Mule, J. C. Lopez-Talavera and W. Mars (2002). "Hepatocytes undergo phenotypic transformation to biliary epithelium in organoid cultures." Hepatology 36(2): 278283.

Michalopoulos, G. K., W. C. Bowen, K. Mulè and D. B. Stolz (2001). "Histological Organization in Hepatocyte Organoid Cultures." The American Journal of Pathology 159(5): 1877-1887. 
Montesano, R., P. Mouron, M. Amherdt and L. Orci (1983). "Collagen matrix promotes reorganization of pancreatic endocrine cell monolayers into islet-like organoids." The Journal of cell biology 97(3): 935939.

Muguruma, K., A. Nishiyama, H. Kawakami, K. Hashimoto and Y. Sasai (2015). "Self-organization of polarized cerebellar tissue in 3D culture of human pluripotent stem cells." Cell Rep 10(4): 537-550.

Munera, J. O. and J. M. Wells (2017). "Generation of Gastrointestinal Organoids from Human Pluripotent Stem Cells." Methods Mol Biol 1597: 167-177.

Nagy, N., A. de la Zerda, G. Kaber, P. Y. Johnson, K. H. Hu, M. J. Kratochvil, K. Yadava, W. Zhao, Y. Cui, G. Navarro, J. P. Annes, T. N. Wight, S. C. Heilshorn, P. L. Bollyky and M. J. Butte (2018).

"Hyaluronan content governs tissue stiffness in pancreatic islet inflammation." J Biol Chem 293(2): 567578.

Nair, G. G., J. S. Liu, H. A. Russ, S. Tran, M. S. Saxton, R. Chen, C. Juang, M. L. Li, V. Q. Nguyen, S. Giacometti, S. Puri, Y. Xing, Y. Wang, G. L. Szot, J. Oberholzer, A. Bhushan and M. Hebrok (2019). "Recapitulating endocrine cell clustering in culture promotes maturation of human stem-cell-derived beta cells." Nat Cell Biol 21(2): 263-274.

Nakano, T., S. Ando, N. Takata, M. Kawada, K. Muguruma, K. Sekiguchi, K. Saito, S. Yonemura, M. Eiraku and Y. Sasai (2012). "Self-formation of optic cups and storable stratified neural retina from human ESCs." Cell Stem Cell 10(6): 771-785.

Nakaya, Y. and G. Sheng (2013). "EMT in developmental morphogenesis." Cancer Lett 341(1): 9-15. Nakaya, Y., E. W. Sukowati and G. Sheng (2013). "Epiblast integrity requires CLASP and Dystroglycanmediated microtubule anchoring to the basal cortex." J Cell Biol 202(4): 637-651.

Ng, S. S., K. Saeb-Parsy, S. J. I. Blackford, J. M. Segal, M. P. Serra, M. Horcas-Lopez, D. Y. No, S. Mastoridis, W. Jassem, C. W. Frank, N. J. Cho, H. Nakauchi, J. S. Glenn and S. T. Rashid (2018). "Human iPS derived progenitors bioengineered into liver organoids using an inverted colloidal crystal poly (ethylene glycol) scaffold." Biomaterials 182: 299-311.

Nie, Y. Z., Y. W. Zheng, M. Ogawa, E. Miyagi and H. Taniguchi (2018). "Human liver organoids generated with single donor-derived multiple cells rescue mice from acute liver failure." Stem Cell Res Ther 9(1): 5 .

Ogawa, M., S. Ogawa, C. E. Bear, S. Ahmadi, S. Chin, B. Li, M. Grompe, G. Keller, B. M. Kamath and A. Ghanekar (2015). "Directed differentiation of cholangiocytes from human pluripotent stem cells." Nat Biotechnol 33(8): 853-861.

Ogoke, O., J. Oluwole and N. Parashurama (2017). "Bioengineering considerations in liver regenerative medicine." J Biol Eng 11: 46.

Okuda, S., N. Takata, Y. Hasegawa, M. Kawada, Y. Inoue, T. Adachi, Y. Sasai and M. Eiraku (2018).

"Strain-triggered mechanical feedback in self-organizing optic-cup morphogenesis." Sci Adv 4(11): eaau1354.

Ortega-Prieto, A. M., J. K. Skelton, S. N. Wai, E. Large, M. Lussignol, G. Vizcay-Barrena, D. Hughes, R. A. Fleck, M. Thursz, M. T. Catanese and M. Dorner (2018). "3D microfluidic liver cultures as a physiological preclinical tool for hepatitis B virus infection." Nature Communications 9.

Parashurama, N., Y. Nahmias, C. H. Cho, D. van Poll, A. W. Tilles, F. Berthiaume and M. L. Yarmush (2008). "Activin alters the kinetics of endoderm induction in embryonic stem cells cultured on collagen gels." Stem Cells 26(2): 474-484.

Paszek, M. J., D. Boettiger, V. M. Weaver and D. A. Hammer (2009). "Integrin clustering is driven by mechanical resistance from the glycocalyx and the substrate." PLoS Comput Biol 5(12): e1000604.

Peng, W. C., C. Y. Logan, M. Fish, T. Anbarchian, F. Aguisanda, A. Alvarez-Varela, P. Wu, Y. Jin, J.

Zhu, B. Li, M. Grompe, B. Wang and R. Nusse (2018). "Inflammatory Cytokine TNFalpha Promotes the Long-Term Expansion of Primary Hepatocytes in 3D Culture." Cell 175(6): 1607-1619 e1615.

Peter, I. S. and E. H. Davidson (2011). "Evolution of gene regulatory networks controlling body plan development." Cell 144(6): 970-985.

Planas-Paz, L., T. Sun, M. Pikiolek, N. R. Cochran, S. Bergling, V. Orsini, Z. Yang, F. Sigoillot, J. Jetzer, M. Syed, M. Neri, S. Schuierer, L. Morelli, P. S. Hoppe, W. Schwarzer, C. M. Cobos, J. L. Alford, L. 
Zhang, R. Cuttat, A. Waldt, N. Carballido-Perrig, F. Nigsch, B. Kinzel, T. B. Nicholson, Y. Yang, X. Mao, L. M. Terracciano, C. Russ, J. S. Reece-Hoyes, C. Gubser Keller, A. W. Sailer, T. Bouwmeester, L. E. Greenbaum, J. J. Lugus, F. Cong, G. McAllister, G. R. Hoffman, G. Roma and J. S. Tchorz (2019). "YAP, but Not RSPO-LGR4/5, Signaling in Biliary Epithelial Cells Promotes a Ductular Reaction in Response to Liver Injury." Cell Stem Cell 25(1): 39-53 e10.

Raikwar, S. P., E. M. Kim, W. I. Sivitz, C. Allamargot, D. R. Thedens and N. Zavazava (2015). "Human iPS cell-derived insulin producing cells form vascularized organoids under the kidney capsules of diabetic mice." PLoS One 10(1): e0116582.

Ramachandran, S. D., K. Schirmer, B. Munst, S. Heinz, S. Ghafoory, S. Wolfl, K. Simon-Keller, A. Marx, C. I. Oie, M. P. Ebert, H. Walles, J. Braspenning and K. Breitkopf-Heinlein (2015). "In Vitro Generation of Functional Liver Organoid-Like Structures Using Adult Human Cells." PLoS One 10(10): e0139345.

Ramaiahgari, S. C., M. W. den Braver, B. Herpers, V. Terpstra, J. N. Commandeur, B. van de Water and L. S. Price (2014). "A 3D in vitro model of differentiated HepG2 cell spheroids with improved liver-like properties for repeated dose high-throughput toxicity studies." Arch Toxicol 88(5): 1083-1095.

Rashidi, H., N. T. Luu, S. M. Alwahsh, M. Ginai, S. Alhaque, H. Dong, R. A. Tomaz, B. Vernay, V. Vigneswara, J. M. Hallett, A. Chandrashekran, A. Dhawan, L. Vallier, M. Bradley, A. Callanan, S. J. Forbes, P. N. Newsome and D. C. Hay (2018). "3D human liver tissue from pluripotent stem cells displays stable phenotype in vitro and supports compromised liver function in vivo." Arch Toxicol 92(10): 3117-3129.

Rios, A. C. and H. Clevers (2018). "Imaging organoids: a bright future ahead." Nat Methods 15(1): 24-26. Roose, T., P. A. Netti, L. L. Munn, Y. Boucher and R. K. Jain (2003). "Solid stress generated by spheroid growth estimated using a linear poroelasticity model." Microvasc Res 66(3): 204-212.

Sampaziotis, F., M. C. de Brito, I. Geti, A. Bertero, N. R. Hannan and L. Vallier (2017). "Directed differentiation of human induced pluripotent stem cells into functional cholangiocyte-like cells." Nat Protoc 12(4): 814-827.

Sampaziotis, F., A. W. Justin, O. C. Tysoe, S. Sawiak, E. M. Godfrey, S. S. Upponi, R. L. Gieseck, 3rd, M. C. de Brito, N. L. Berntsen, M. J. Gomez-Vazquez, D. Ortmann, L. Yiangou, A. Ross, J. Bargehr, A. Bertero, M. C. F. Zonneveld, M. T. Pedersen, M. Pawlowski, L. Valestrand, P. Madrigal, N. Georgakopoulos, N. Pirmadjid, G. M. Skeldon, J. Casey, W. Shu, P. M. Materek, K. E. Snijders, S. E. Brown, C. A. Rimland, I. Simonic, S. E. Davies, K. B. Jensen, M. Zilbauer, W. T. H. Gelson, G. J. Alexander, S. Sinha, N. R. F. Hannan, T. A. Wynn, T. H. Karlsen, E. Melum, A. E. Markaki, K. SaebParsy and L. Vallier (2017). "Reconstruction of the mouse extrahepatic biliary tree using primary human extrahepatic cholangiocyte organoids." Nat Med 23(8): 954-963.

Sato, T., R. G. Vries, H. J. Snippert, M. van de Wetering, N. Barker, D. E. Stange, J. H. van Es, A. Abo, P. Kujala, P. J. Peters and H. Clevers (2009). "Single Lgr5 stem cells build crypt-villus structures in vitro without a mesenchymal niche." Nature 459(7244): 262-265.

Schwartz, A. L., S. E. Fridovich, B. B. Knowles and H. F. Lodish (1981). "Characterization of the asialoglycoprotein receptor in a continuous hepatoma line." J Biol Chem 256(17): 8878-8881.

Segal, J. M., D. Kent, D. J. Wesche, S. S. Ng, M. Serra, B. Oules, G. Kar, G. Emerton, S. J. I. Blackford, S. Darmanis, R. Miquel, T. V. Luong, R. Yamamoto, A. Bonham, W. Jassem, N. Heaton, A. Vigilante, A. King, R. Sancho, S. Teichmann, S. R. Quake, H. Nakauchi and S. T. Rashid (2019). "Single cell analysis of human foetal liver captures the transcriptional profile of hepatobiliary hybrid progenitors." Nat Commun 10(1): 3350.

Shi, Y., H. Inoue, J. C. Wu and S. Yamanaka (2017). "Induced pluripotent stem cell technology: a decade of progress." Nat Rev Drug Discov 16(2): 115-130.

Si-Tayeb, K., F. P. Lemaigre and S. A. Duncan (2010). "Organogenesis and development of the liver." Dev Cell 18(2): 175-189.

Simerly, C., C. Navara, S. H. Hyun, B. C. Lee, S. K. Kang, S. Capuano, G. Gosman, T. Dominko, K. Y. Chong, D. Compton, W. S. Hwang and G. Schatten (2004). "Embryogenesis and blastocyst development 
after somatic cell nuclear transfer in nonhuman primates: overcoming defects caused by meiotic spindle extraction." Dev Biol 276(2): 237-252.

Simunovic, M. and A. H. Brivanlou (2017). "Embryoids, organoids and gastruloids: new approaches to understanding embryogenesis." Development 144(6): 976-985.

Skardal, A., T. Shupe and A. Atala (2016). "Organoid-on-a-chip and body-on-a-chip systems for drug screening and disease modeling." Drug Discov Today 21(9): 1399-1411.

Soltanian, A., Z. Ghezelayagh, Z. Mazidi, M. Halvaei, S. Mardpour, M. K. Ashtiani, E. Hajizadeh-Saffar, Y. Tahamtani and H. Baharvand (2018). "Generation of functional human pancreatic organoids by transplants of embryonic stem cell derivatives in a 3D-printed tissue trapper." J Cell Physiol.

Soroka, C. J., D. N. Assis, L. S. Alrabadi, S. Roberts, L. Cusack, A. B. Jaffe and J. L. Boyer (2019). "Bile-Derived Organoids From Patients With Primary Sclerosing Cholangitis Recapitulate Their Inflammatory Immune Profile." Hepatology 70(3): 871-882.

Spence, J. R., C. N. Mayhew, S. A. Rankin, M. F. Kuhar, J. E. Vallance, K. Tolle, E. E. Hoskins, V. V. Kalinichenko, S. I. Wells, A. M. Zorn, N. F. Shroyer and J. M. Wells (2011). "Directed differentiation of human pluripotent stem cells into intestinal tissue in vitro." Nature 470(7332): 105-109.

Steinberg, M. S. (1963). "Reconstruction of tissues by dissociated cells. Some morphogenetic tissue movements and the sorting out of embryonic cells may have a common explanation." Science 141(3579): 401-408.

Stylianopoulos, T., J. D. Martin, V. P. Chauhan, S. R. Jain, B. Diop-Frimpong, N. Bardeesy, B. L. Smith, C. R. Ferrone, F. J. Hornicek, Y. Boucher, L. L. Munn and R. K. Jain (2012). "Causes, consequences, and remedies for growth-induced solid stress in murine and human tumors." Proc Natl Acad Sci U S A 109(38): 15101-15108.

Suga, H., T. Kadoshima, M. Minaguchi, M. Ohgushi, M. Soen, T. Nakano, N. Takata, T. Wataya, K. Muguruma, H. Miyoshi, S. Yonemura, Y. Oiso and Y. Sasai (2011). "Self-formation of functional adenohypophysis in three-dimensional culture." Nature 480(7375): 57-62.

Sugimoto, S., K. Harada, T. Shiotani, S. Ikeda, N. Katsura, I. Ikai, T. Mizuguchi, K. Hirata, Y. Yamaoka and T. Mitaka (2005). "Hepatic organoid formation in collagen sponge of cells isolated from human liver tissues." Tissue Engineering 11(3-4): 626-633.

Sugimoto, S., K. Harada, T. Shiotani, S. Ikeda, N. Katsura, I. Ikai, T. Mizuguchi, K. Hirata, Y. Yamaoka and T. Mitaka (2005). "Hepatic organoid formation in collagen sponge of cells isolated from human liver tissues." Tissue Eng 11(3-4): 626-633.

Takahashi, Y., K. Sekine, T. Kin, T. Takebe and H. Taniguchi (2018). "Self-Condensation Culture Enables Vascularization of Tissue Fragments for Efficient Therapeutic Transplantation." Cell Rep 23(6): 1620-1629.

Takasato, M., P. X. Er, H. S. Chiu, B. Maier, G. J. Baillie, C. Ferguson, R. G. Parton, E. J. Wolvetang, M. S. Roost, S. M. Chuva de Sousa Lopes and M. H. Little (2015). "Kidney organoids from human iPS cells contain multiple lineages and model human nephrogenesis." Nature 526(7574): 564-568.

Takebe, T., K. Sekine, M. Enomura, H. Koike, M. Kimura, T. Ogaeri, R. R. Zhang, Y. Ueno, Y. W. Zheng, N. Koike, S. Aoyama, Y. Adachi and H. Taniguchi (2013). "Vascularized and functional human liver from an iPSC-derived organ bud transplant." Nature 499(7459): 481-484.

Takebe, T., K. Sekine, M. Kimura, E. Yoshizawa, S. Ayano, M. Koido, S. Funayama, N. Nakanishi, T. Hisai, T. Kobayashi, T. Kasai, R. Kitada, A. Mori, H. Ayabe, Y. Ejiri, N. Amimoto, Y. Yamazaki, S. Ogawa, M. Ishikawa, Y. Kiyota, Y. Sato, K. Nozawa, S. Okamoto, Y. Ueno and H. Taniguchi (2017). "Massive and Reproducible Production of Liver Buds Entirely from Human Pluripotent Stem Cells." Cell Rep 21(10): 2661-2670.

Takebe, T., R. R. Zhang, H. Koike, M. Kimura, E. Yoshizawa, M. Enomura, N. Koike, K. Sekine and H. Taniguchi (2014). "Generation of a vascularized and functional human liver from an iPSC-derived organ bud transplant." Nat Protoc 9(2): 396-409.

Tam, P. P. and D. A. Loebel (2007). "Gene function in mouse embryogenesis: get set for gastrulation." Nat Rev Genet 8(5): 368-381. 
Tanimizu, N., M. Nishikawa, H. Saito, T. Tsujimura and A. Miyajima (2003). "Isolation of hepatoblasts based on the expression of Dlk/Pref-1." J Cell Sci 116(Pt 9): 1775-1786.

Tarlow, B. D., M. J. Finegold and M. Grompe (2014). "Clonal tracing of Sox9+ liver progenitors in mouse oval cell injury." Hepatology 60(1): 278-289.

Tsai, S., L. McOlash, K. Palen, B. Johnson, C. Duris, Q. Yang, M. B. Dwinell, B. Hunt, D. B. Evans, J. Gershan and M. A. James (2018). "Development of primary human pancreatic cancer organoids, matched stromal and immune cells and 3D tumor microenvironment models." BMC Cancer 18(1): 335.

Visvader, J. E. and H. Clevers (2016). "Tissue-specific designs of stem cell hierarchies." Nat Cell Biol 18(4): 349-355.

Vyas, D., P. M. Baptista, M. Brovold, E. Moran, M. Brovold, B. Gaston, C. Booth, M. Samuel, A. Atala and S. Soker (2017). "Self-assembled liver organoids recapitulate hepato-biliary organogenesis in vitro." Hepatology.

Walsh, A. J., R. S. Cook, M. E. Sanders, L. Aurisicchio, G. Ciliberto, C. L. Arteaga and M. C. Skala (2014). "Quantitative Optical Imaging of Primary Tumor Organoid Metabolism Predicts Drug Response in Breast Cancer." Cancer Research 74(18): 5184-5194.

Walsh, A. J., R. S. Cook and M. C. Skala (2017). "Functional Optical Imaging of Primary Human Tumor Organoids: Development of a Personalized Drug Screen." J Nucl Med 58(9): 1367-1372.

Wang, B., L. Zhao, M. Fish, C. Y. Logan and R. Nusse (2015). "Self-renewing diploid Axin2(+) cells fuel homeostatic renewal of the liver." Nature 524(7564): 180-185.

Wang, W., S. Jin and K. Ye (2017). "Development of Islet Organoids from H9 Human Embryonic Stem Cells in Biomimetic 3D Scaffolds." Stem cells and development 26(6): 394-404.

Warmflash, A., B. Sorre, F. Etoc, E. D. Siggia and A. H. Brivanlou (2014). "A method to recapitulate early embryonic spatial patterning in human embryonic stem cells." Nat Methods 11(8): 847-854. Weliky, M. and G. Oster (1990). "The mechanical basis of cell rearrangement. I. Epithelial morphogenesis during Fundulus epiboly." Development 109(2): 373-386.

Willadsen, M., M. Chaise, I. Yarovoy, A. Q. Zhang and N. Parashurama (2018). "Engineering molecular imaging strategies for regenerative medicine." Bioeng Transl Med 3(3): 232-255.

Woolbright, B. L., B. W. Bridges, W. Dunn, J. C. Olson, S. A. Weinman and H. Jaeschke (2017). "Cell Death and Prognosis of Mortality in Alcoholic Hepatitis Patients Using Plasma Keratin-18." Gene Expr 17(4): 301-312.

Xu, L., A. Y. Hui, E. Albanis, M. J. Arthur, S. M. O'Byrne, W. S. Blaner, P. Mukherjee, S. L. Friedman and F. J. Eng (2005). "Human hepatic stellate cell lines, LX-1 and LX-2: new tools for analysis of hepatic fibrosis." Gut 54(1): 142-151.

Yokoyama, Y., Y. Sasaki, N. Terasaki, T. Kawataki, K. Takekawa, Y. Iwase, T. Shimizu, S. Sanoh and S. Ohta (2018). "Comparison of Drug Metabolism and Its Related Hepatotoxic Effects in HepaRG, Cryopreserved Human Hepatocytes, and HepG2 Cell Cultures." Biol Pharm Bull 41(5): 722-732.

Zhang, F., W. Wang, Y. Long, H. Liu, J. Cheng, L. Guo, R. Li, C. Meng, S. Yu, Q. Zhao, S. Lu, L. Wang, H. Wang and D. Wen (2018). "Characterization of drug responses of mini patient-derived xenografts in mice for predicting cancer patient clinical therapeutic response." Cancer Commun (Lond) 38(1): 60. Zhang, R. R., Y. W. Zheng, B. Li, Y. Z. Nie, Y. Ueno, T. Tsuchida and H. Taniguchi (2018). "Hepatic stem cells with self-renewal and liver repopulation potential are harbored in CDCP1-positive subpopulations of human fetal liver cells." Stem Cell Res Ther 9(1): 29.

Zheng, Y., X. Xue, Y. Shao, S. Wang, S. N. Esfahani, Z. Li, J. M. Muncie, J. N. Lakins, V. M. Weaver, D. L. Gumucio and J. Fu (2019). "Controlled modelling of human epiblast and amnion development using stem cells." Nature 573(7774): 421-425.

Zhou, T., L. Tan, G. Y. Cederquist, Y. Fan, B. J. Hartley, S. Mukherjee, M. Tomishima, K. J. Brennand, Q. Zhang, R. E. Schwartz, T. Evans, L. Studer and S. Chen (2017). "High-Content Screening in hPSCNeural Progenitors Identifies Drug Candidates that Inhibit Zika Virus Infection in Fetal-like Organoids and Adult Brain." Cell Stem Cell 21(2): 274-283 e275.

Zhou, V. X., M. Lolas and T. T. Chang (2017). "Direct orthotopic implantation of hepatic organoids." J Surg Res 211: 251-260. 
Zhou, V. X., M. Lolas and T. T. Chang (2017). "Direct orthotopic implantation of hepatic organoids." Journal of Surgical Research 211: 251-260.

Zhu, S., M. Rezvani, J. Harbell, A. N. Mattis, A. R. Wolfe, L. Z. Benet, H. Willenbring and S. Ding (2014). "Mouse liver repopulation with hepatocytes generated from human fibroblasts." Nature 508(7494): 93-97.

\section{Figure Legends.}

\section{Figure 1. Applications of hPSC and organoids.}

With the advent of personalized hPSCs (left), scientists and engineers were able to conceive of not only therapy after lineage-specific differentiation, but also moved forward with disease modeling and drug development. These same hPSC-progenitors, prior to lineage-specific differentiation, can be placed in a 3D culture system designed for organoid formation (bottom, right). Here, they self-assemble, and they are believed to become further committed to certain lineages by staying spatially restricted. Finally, the cells mature into an organoid, as a miniature model of an organ. Organoids can be also formed by isolation of adult stem cells or tissue in a similar manner, and used for tissue replacement, disease modeling, and drug development. Just like hPSC, organoids are self-renewing.

\section{Figure 2. Cellular dissection and biological engineering of organoids.}

A). A solid or hollow organ typically has a microstructure that repeats across the organ, often conferring the organ's function. Organs can be digested into their cellular constituents, which include functional, parenchymal cells (P1, P2) and supporting cells (S), and adult stem cells/progenitors (ASC-p). hPSC progenitors (hPSC-p) can also be used. Bioprocessing techniques (Bio.) are techniques used to engineer organoids. B). Repeating structural / functional units of organs can be created with organoids. Organoids primarily derived from parenchymal cells ( $\mathrm{P} 1, \mathrm{P} 2)$, although relatively simple to create, lack the ability to mimic organ architecture, although they may demonstrate organ function. In contrast, organoids derived from both parenchymal (P1, P2) and supporting cells (S) can exhibit organ function in addition to mimicking organ architecture. If adult stem cell progenitors (ASC-p) form the organ of interest are used, the ASC-p will give rise to parenchymal cells P1 and P2, but not supporting cells (S). Thus, the organoid will also be self-renewable, but without supporting cells, may lack full architecture. If hPSC-derived progenitors (PSC-p) are used together with supporting cells (S), the PSC-p will give rise to parenchymal cells P1 and P2, and the organoid will retain organ microarchitecture and will be personalized. If bioprocessing techniques (Bio.) are used to make organoids more precisely, then the organoids will also be uniform.

Figure 3. In vitro 3D culture techniques for organoid engineering. 
In vitro models of organoids have utilized a number of culture techniques to mimic the in vivo environment. Several self-organizing culture approaches have been explore including low attachment plates, embryoid body plates, the hanging drop technique and agarose coated plate culture. In these techniques cells are seeded onto specially treated surfaces and allowed to aggregate over time. Threedimensional culture (3D) gel based methods whereby cell aggregates are embedded or cultured on top of an extracellular matrix have also been utilized to form organoids.

\section{Figure 4. Hepatocyte derivation from hPSC.}

Human pluripotent stem cells (hPSC) derived hepatocytes can be utilized to make functional hepatic or hepatic/biliary organoids that recapitulate minimal in vivo liver function. At a cellular level, creating fully mature hepatocytes is still a challenge for the field and remains a limitation to current liver/biliary organoid models for various applications. Through embryogenesis, hepatocytes are typically derived through a two-step pathway that involves differentiation to definitive endoderm and then followed by hepatic progenitor cell induction. Functionally mature hepatocytes express markers such as Albumin, Transferrin, and Asialoglycoprotein Receptor 1 (ASGPR1).

\section{Figure 5. Cholangiocyte derivation from hPSC.}

Human pluripotent stem cells (hPSC) derived cholangiocytes can be utilized to make functional biliary or hepatic/biliary organoids that recapitulate minimal in vivo biliary function. At a cellular level, creating fully mature cholangiocytes also remains a challenge for the field and remains a limitation to current liver/biliary organoid models for various applications. In addition, during embryogenesis, cholangiocytes proceed through a two- step differentiation pathway into definitive endoderm followed by cholangiocyte progenitor induction. Functionally mature cholangiocytes express markers such as Sox9, Ck19, and HNF6.

\section{Figure 6. Pancreatic cell derivation from hPSC.}

Human pluripotent stem cells (hPSC) derived pancreatic cells can be utilized to make functional pancreatic organoids that recapitulate minimal in vivo liver function. At a cellular level, creating fully mature pancreatic cells is still a challenge for the field and remains a limitation to current pancreatic organoid models for various applications. In vitro derived functional pancreatic cells (acinar or endocrine) are derived from pancreatic endoderm and express insulin, glucagon, somatostatin (endocrine) or PTF1a, amylase, and CPA1 (acinar). 


\section{Figure 1.}

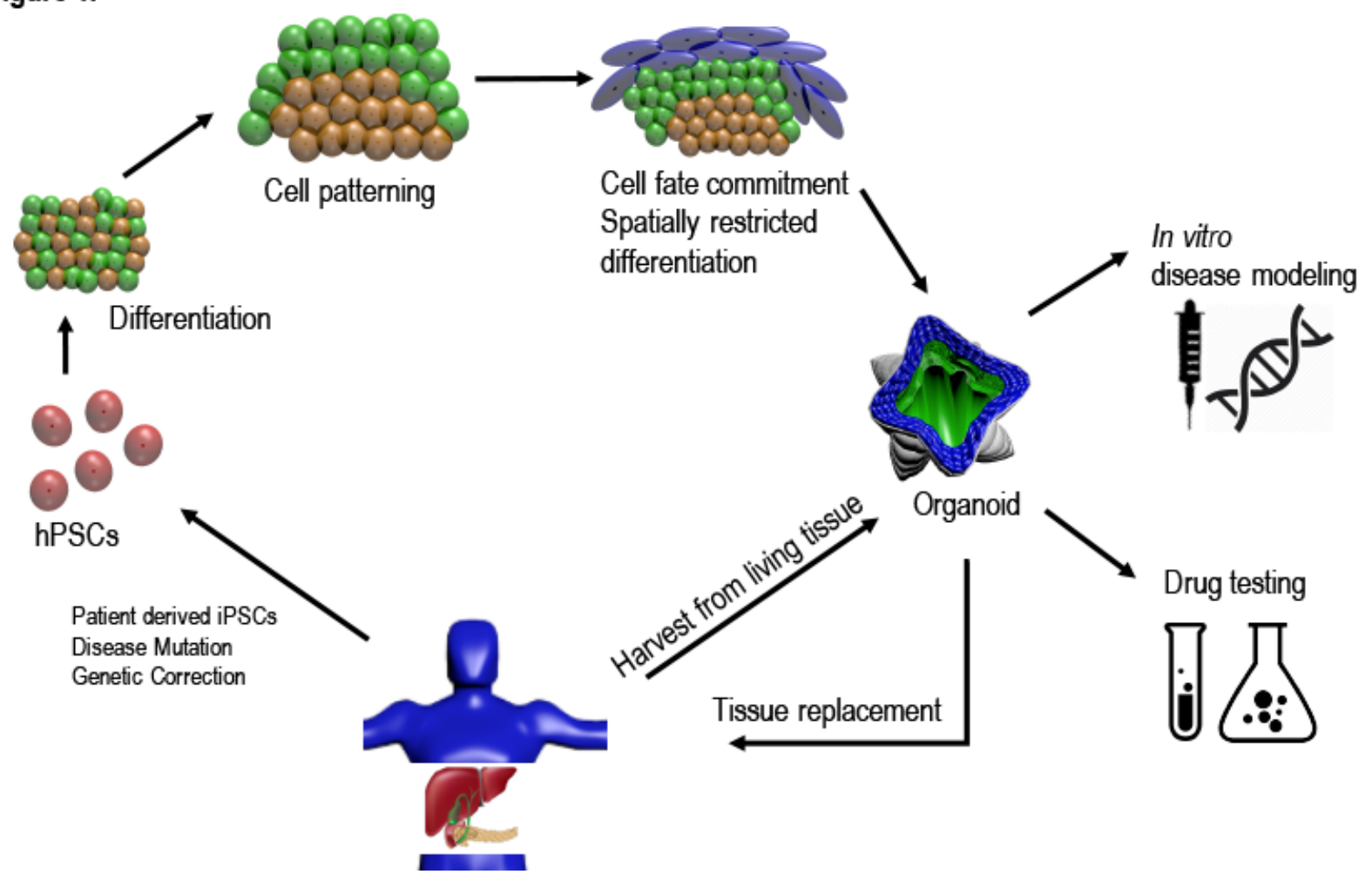




\section{Figure 2.}

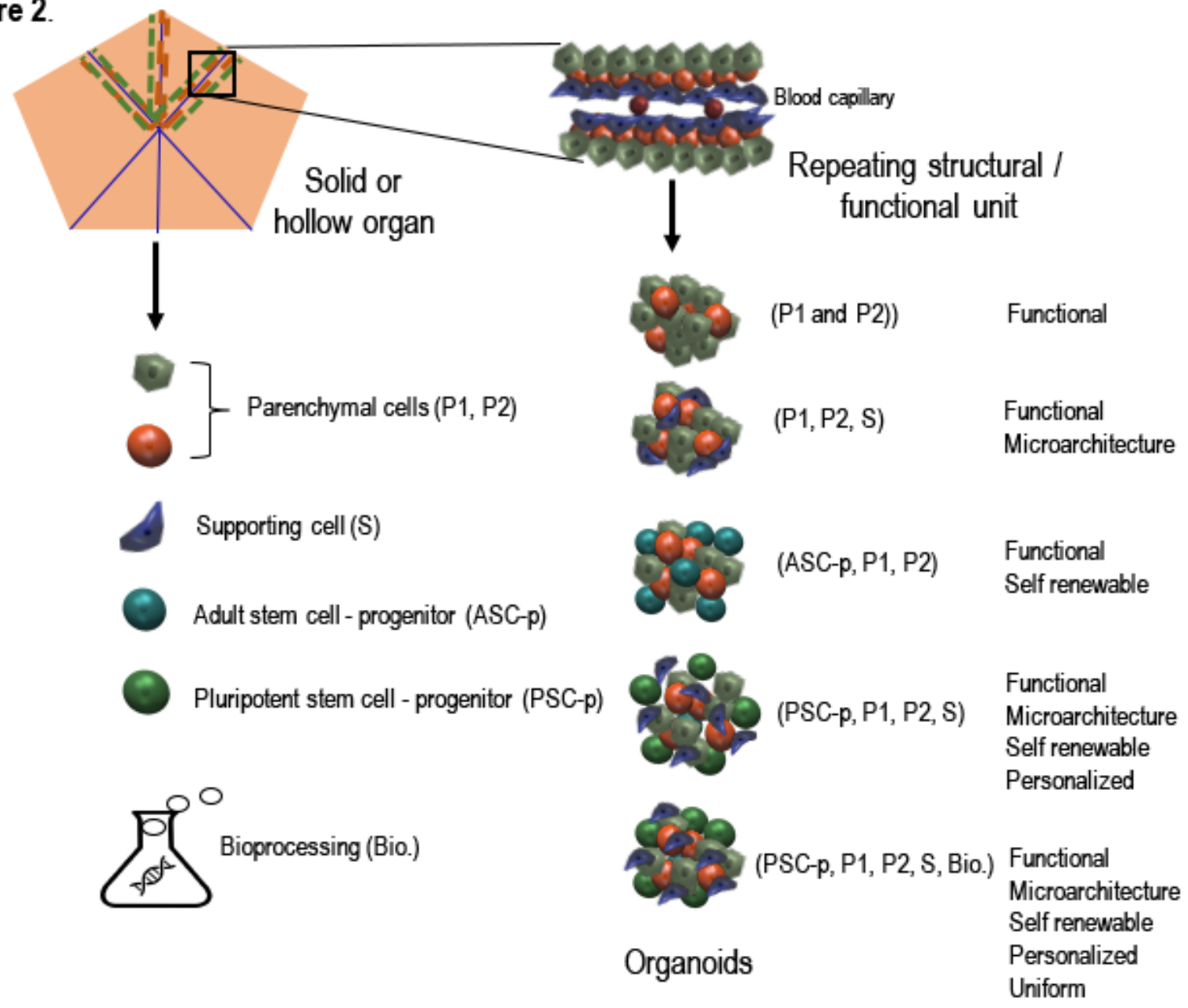


Figure 3.

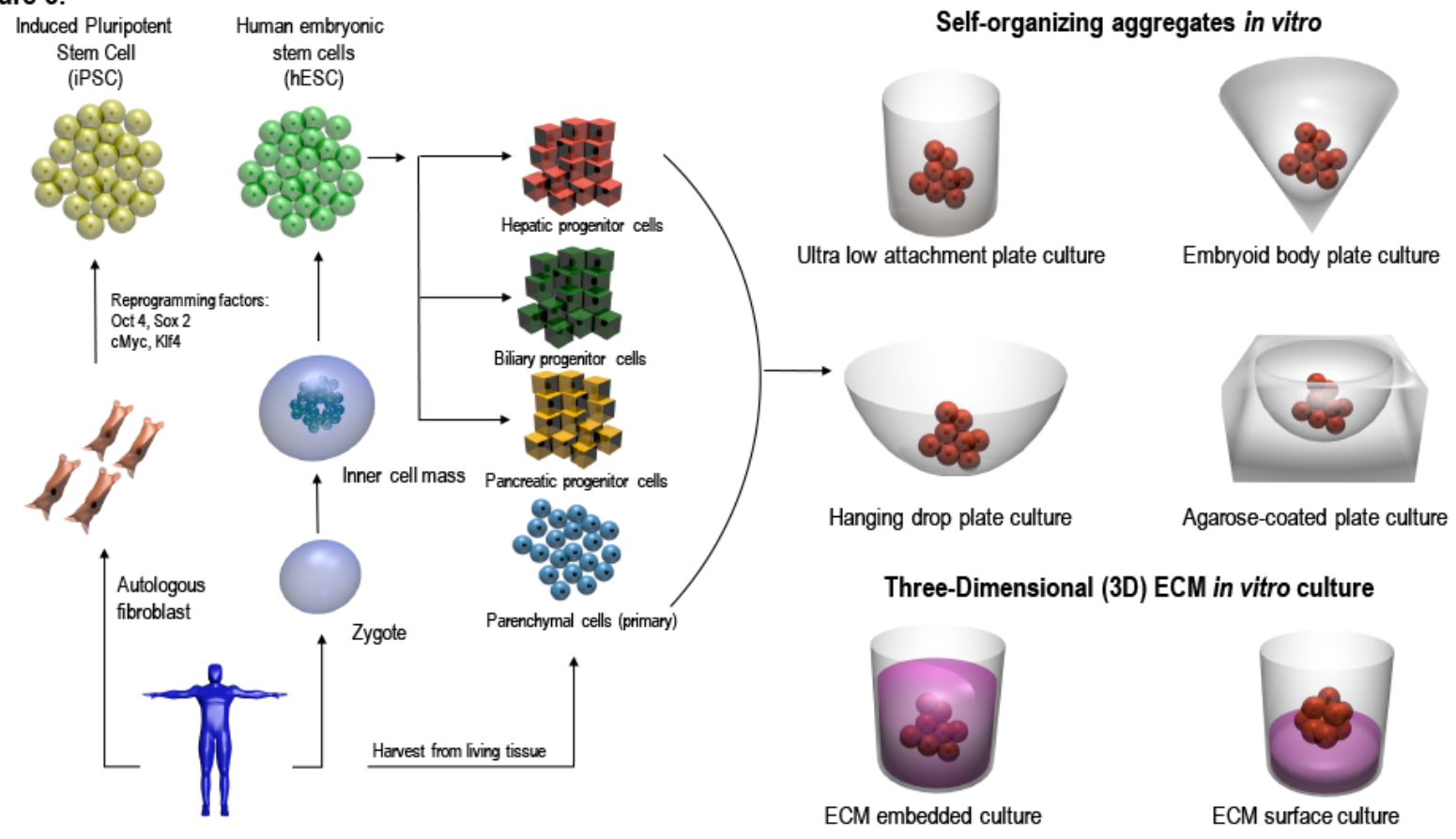




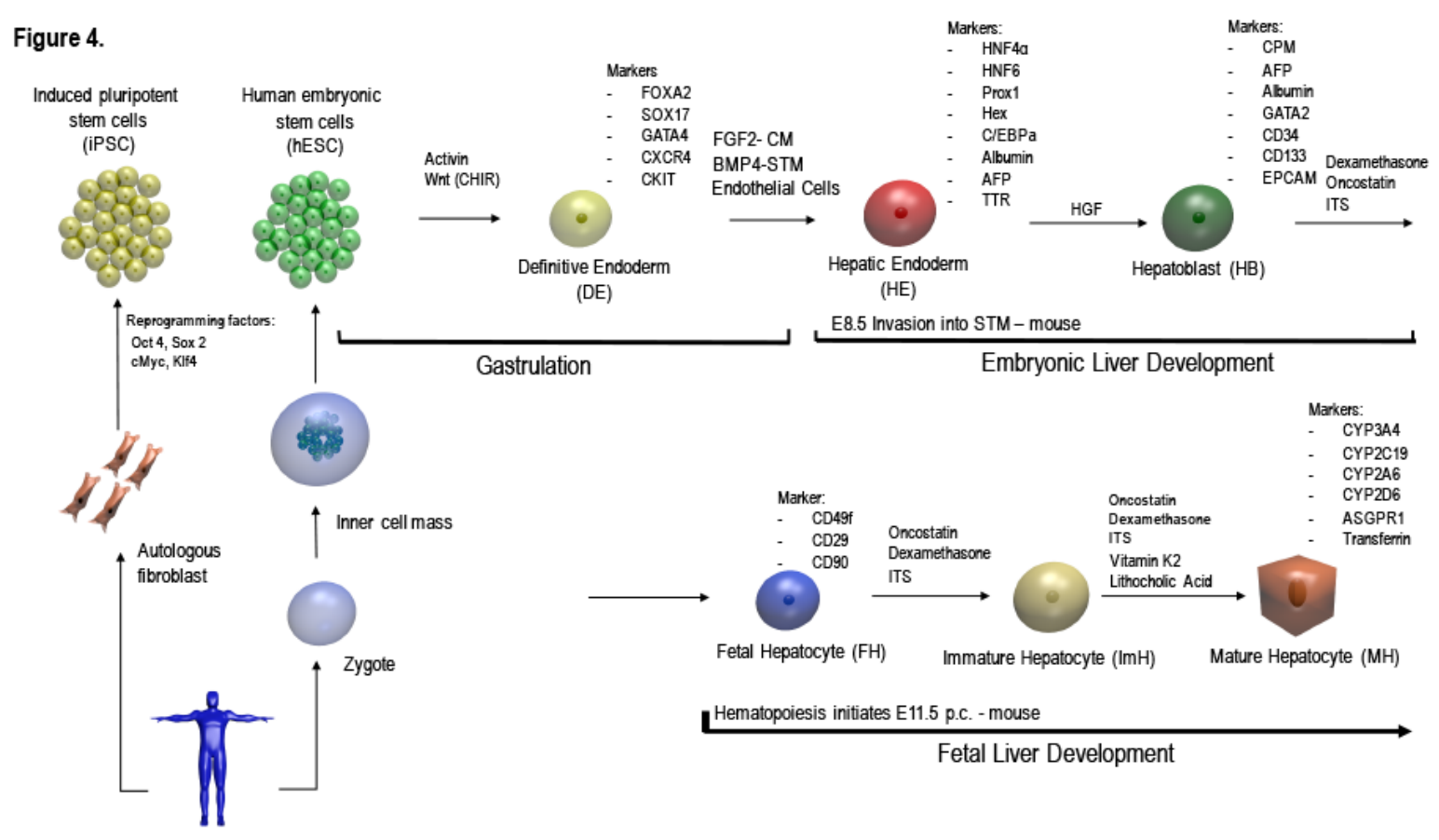




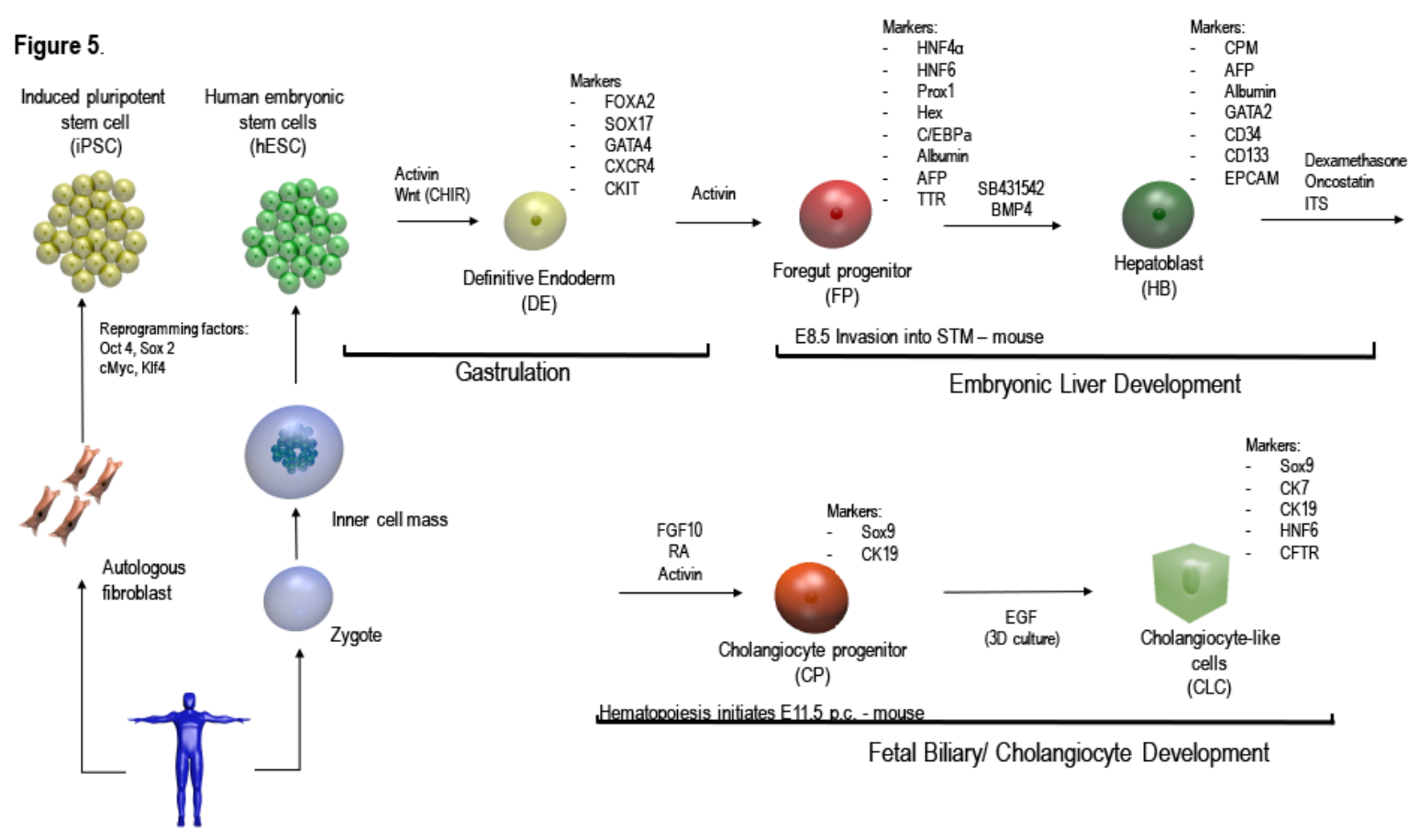




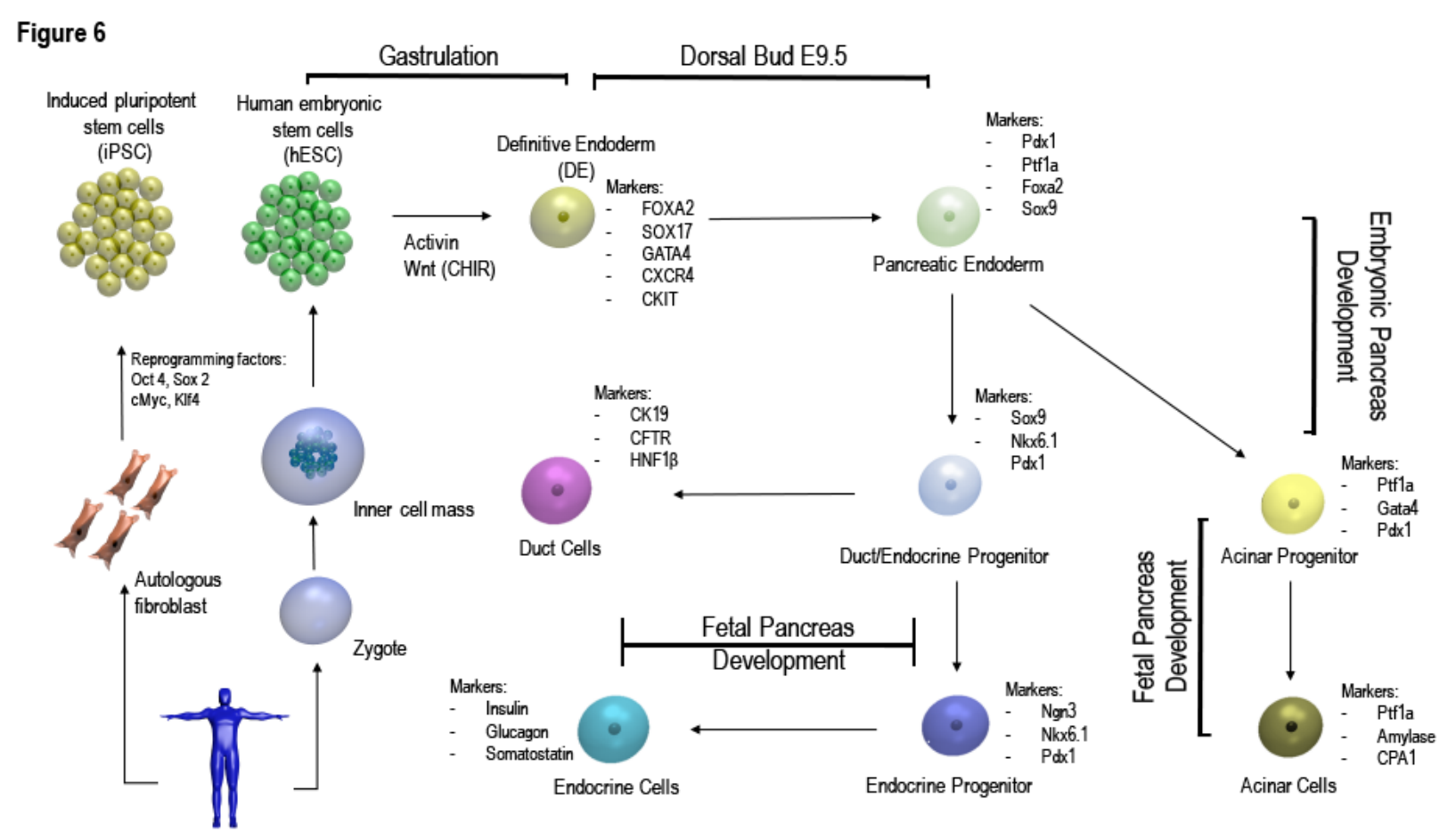

